\title{
Association of Diet Quality with Fall Risk among Community- Dwelling Older Adults in a Fall-Prevention Program
}

\author{
Jae Hyun Kim \\ West Virginia University, jk0118@mix.wvu.edu
}

Follow this and additional works at: https://researchrepository.wvu.edu/etd

Part of the Other Nutrition Commons

\section{Recommended Citation}

Kim, Jae Hyun, "Association of Diet Quality with Fall Risk among Community-Dwelling Older Adults in a Fall-Prevention Program" (2020). Graduate Theses, Dissertations, and Problem Reports. 7504.

https://researchrepository.wvu.edu/etd/7504

This Thesis is protected by copyright and/or related rights. It has been brought to you by the The Research Repository @ WVU with permission from the rights-holder(s). You are free to use this Thesis in any way that is permitted by the copyright and related rights legislation that applies to your use. For other uses you must obtain permission from the rights-holder(s) directly, unless additional rights are indicated by a Creative Commons license in the record and/ or on the work itself. This Thesis has been accepted for inclusion in WVU Graduate Theses, Dissertations, and Problem Reports collection by an authorized administrator of The Research Repository @ WVU. For more information, please contact researchrepository@mail.wvu.edu. 


\title{
Association of Diet Quality with Fall Risk among Community-Dwelling Older Adults in a Fall-Prevention Program
}

\author{
Jae Hyun Kim
}

Thesis submitted to the Davis College of Agriculture, Natural Resources and Design at West Virginia University

\author{
In partial fulfillment of the requirements for the degree of \\ Master of Science \\ In Nutritional and Food Science
}

\author{
Melissa Ventura-Marra, PhD, RDN, Chair \\ Ida Holásková, $\mathrm{PhD}$ \\ Dina Jones, PT, PhD \\ Department of Animal and Nutritional Sciences \\ Morgantown, West Virginia
}

2020

Keywords: falls; fall risk factors; STEADI; diet; diet quality; protein; DST; functional measures; older adults

Copyright 2020 Jae Hyun Kim 


\begin{abstract}
Falls are a serious threat to older adults' quality of life. Evidence is lacking regarding the influence of diet on fall risk factors. This study aims to assess the relationship between diet, functional measures, and fall risk among older adults participating in a fall-prevention intervention. Cross-sectional analysis of baseline data from 192 participants with an average age of 70.9 years was conducted using Chi-square tests, t-test, Wilcoxon test, and nominal logistic analysis. Based on Dietary Screening Tool (DST) scores, 39.5\% of participants were classified as nutritionally being "at-risk," 46.1\% were at "possible-risk," and 14.4\% were "notat-risk." Fall risk was assessed using the Stopping Elderly Accidents, Deaths, and Injuries (STEADI) classifications. There were no significant associations between the "not at fall risk" group and "at fall risk" groups in terms of DST total score $(\mathrm{p}=0.97)$, protein score $(\mathrm{p}=0.27)$, multivitamin use $(\mathrm{p}=0.73)$ and DST risk categories $(\mathrm{p}=0.64)$. In the correlation analysis, the DST total scores had a positive correlation with total physical activities $(r=0.1648, p=0.029)$, and a negative correlation with body mass index (BMI) $(r=-0.1496, p=0.04)$ and depression $(\mathrm{r}=-0.1433, \mathrm{p}=0.048)$. In the nominal logistic analysis, neither of the primary predictors, total DST score or DST protein score, showed significance with STEADI fall risk categories. In each model, the Four-Square Step Test (FSST), an indicator of greater risk of future falls, had the closet likelihood ratio test to the statistical trend as the major component associated with STEADI risk categories. A significant relationship between diet, functional measures, and fall risk was not detected.
\end{abstract}




\section{ACKNOWLEDGMENTS}

I would like to acknowledge and thank the people who continuously supported this thesis with constructive feedback. I would like to recognize Dr. Melissa Marra, in particular, as my advisor and mentor for the project. I have much gratitude to her for the great amount of time, energy, and passion that has devoted both to this project and to my success in graduate school. I would also like to thank my committee members, Dr. Dina Jones, and Dr. Ida Holásková, for their guidance and expertise on this project. I would like to show gratitude to Dr. Dina Jones, who provided the data for this thesis. I am very thankful to Dr. Ida Holásková for her assistance in performing and teaching statistical analyses. I am fortunate to have been offered support and guidance by numerous faculty members throughout my graduate career at WVU, and I would like to extend sincere thanks to all who have allowed me to learn from their expertise. I would like to thank WVU research assistants for their contributions to peer review despite their busy schedules. Lastly, I would like to acknowledge the unconditional support I have received from my friends and family through the entirety of this process.

The fall-prevention intervention was supported by the Centers for Disease Control and Prevention, National Center for Injury Control Research Center under Grant No. 1R49CE002109. This cross-sectional analysis of data was supported in part by the USDA National Institute of Food and Agriculture (NIFA) Hatch/Multi-State project no. 1021322, and the West Virginia Agricultural and Forestry Experiment Station. The contents are solely the responsibility of authors and do not necessarily represent the official views of the funding sources. 


\section{TABLE OF CONTENTS}

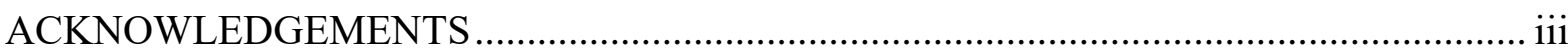

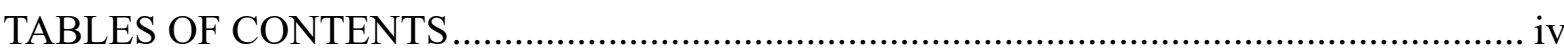

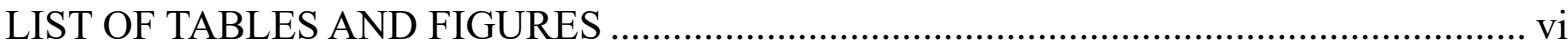

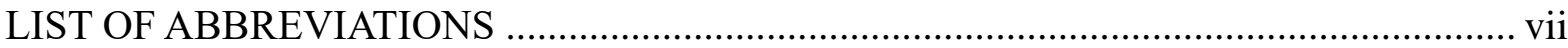

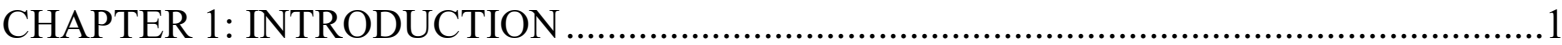

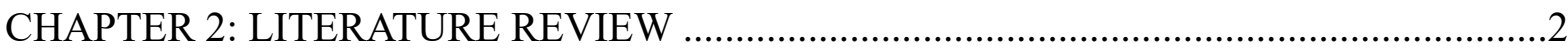

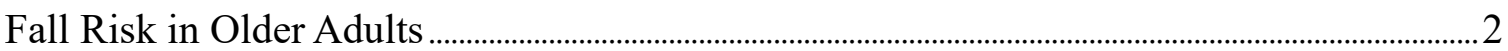

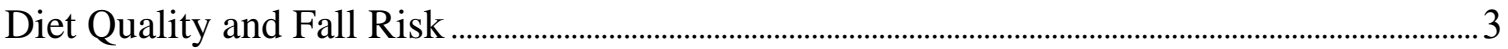

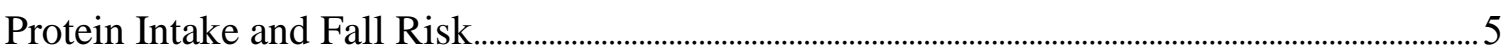

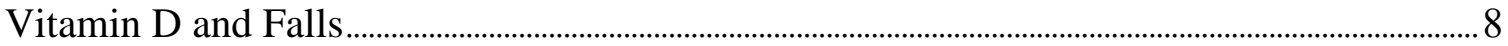

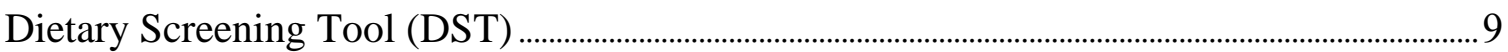

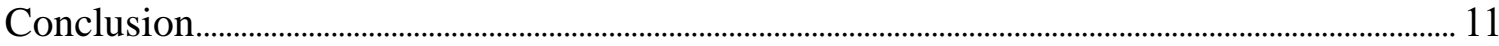

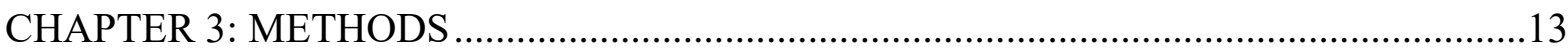

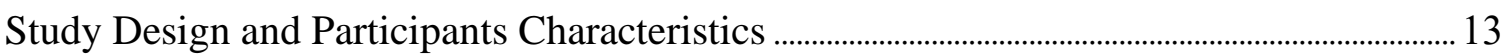

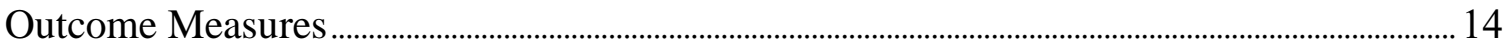

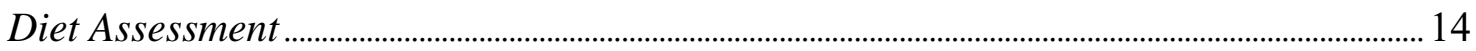

Functional Measures and Physical Activity Assessment .............................................................. 15

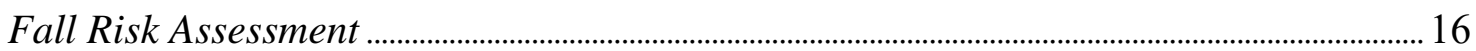

Potential Confounding Variables …………………………………………………………………………….... 17

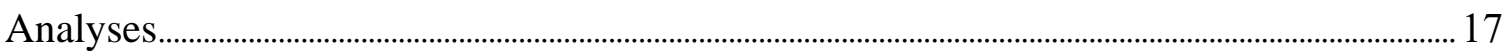

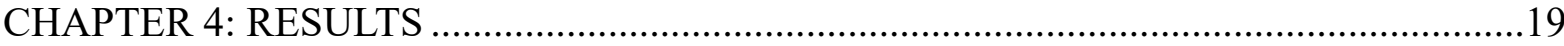

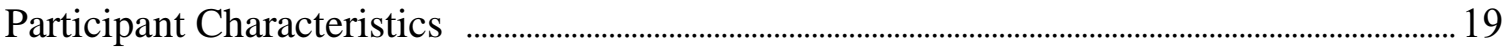

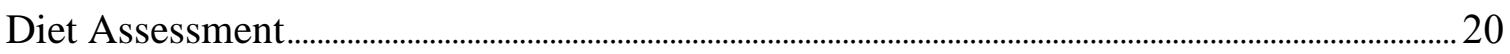

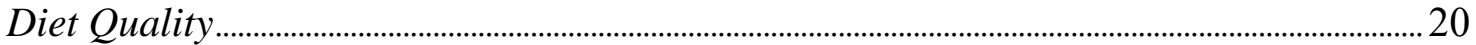

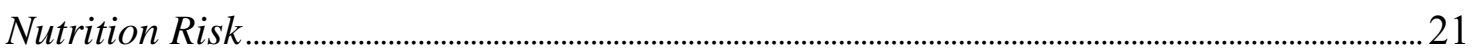

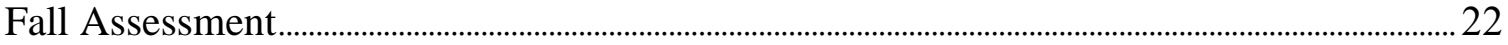

Relationship between Diet and Functional Measures and Fall Risk ……...................................2 23

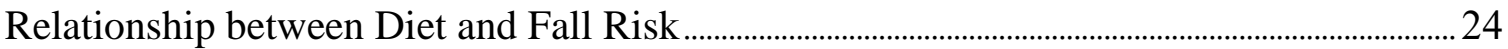

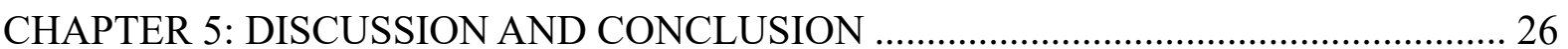

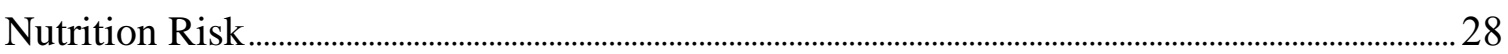




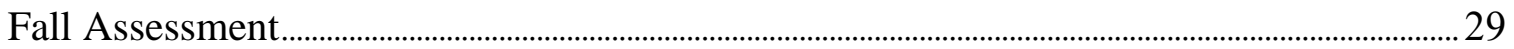

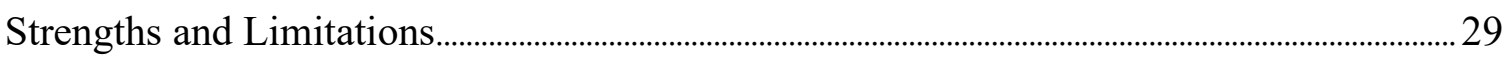

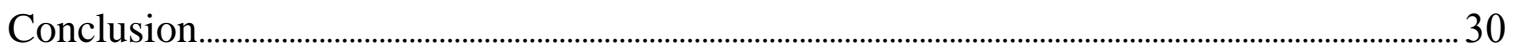

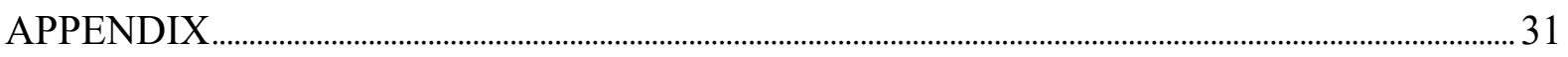

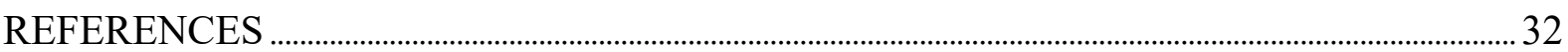




\section{LIST OF TABLES AND FIGURES}

\section{TABLES}

Table 1: Baseline Characteristics among Participants $(\mathrm{N}=192)$ of a Falls Prevention Intervention by DST Nutrition Risk Category .................................................................. 19

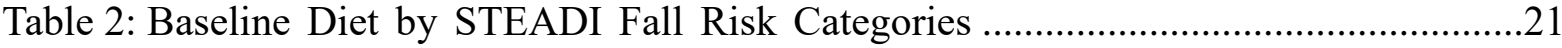

Table 3: STEADI Fall Risk Screening in Participants $(\mathrm{N}=180)$ of a Falls Prevention

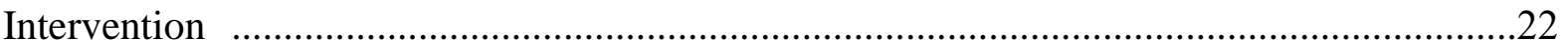

Table 4: Fall Risk Factors by STEADI Risk Category in Participants $(\mathrm{N}=180)$ of a Falls

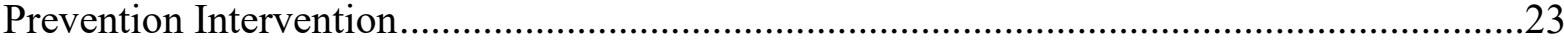

Table 5: Relationship between Sociodemographic Variables, and Functional Measures, and

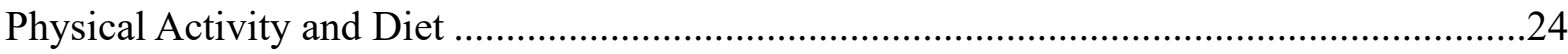

Table 6: The Relationships of the Baseline Diet, Adjustment Variables and STEADI

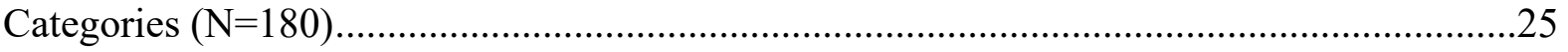

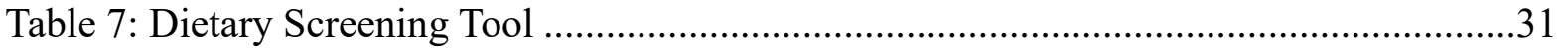

\section{FIGURES}

Figure 1: The Relationship of Diet with Functional Measures, Physical Activity, and Falls ..12

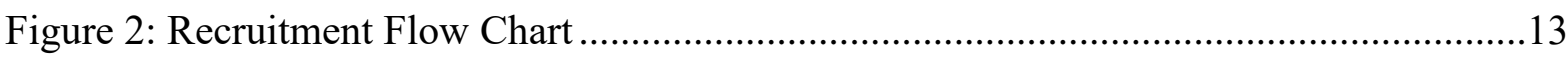

Figure 3: Stopping Elderly Accidents, Deaths, and Injuries (STEADI) Algorithm for Determining Fall Risk Categories: "not at fall risk" and "“at fall risk"..... .16

Figure 4: Dietary Intakes of STEADI Categories by DST Subgroups .20 


\section{LIST OF ABBREVIATIONS}

American and British Geriatrics Societies

AGS/BGS

Body Mass Index

BMI

Centers for Disease Control and Prevention

CDC

Confidence Interval

Dietary Screening Tool

DST

Faith-Based Organization

FBO

Four-Square Step Test

FSST

Falls Efficacy Scale - International

FES-I

Five Times-Sit to Stand

FTSTS

Geriatric Depression Scale

GDS

Healthy Diet Indicator

HDI

National Heart Interviewer Survey

NIHS

National Heart, Lung and Blood Institute

$\mathrm{NIH}$

Odds Ratio

OR

Relative Risk

RR

Six-Item Screener

SIS

Stopping Elderly Accidents, Deaths \& Injuries

STEADI

Timed Up and Go

TUG

United States Preventive Services Task Force

USPSTF 


\section{CHAPTER 1: INTRODUCTION}

Falls are a serious threat to older adults' quality of life [1]. Falls and fall-related injuries are associated with decreased mobility, loss of independence, and fear of falling [1]. Over 3 million older adults are treated in emergency departments [2]. Medical costs related to falls are nearly $\$ 50$ billion annually [3]. Because some falls are preventable, a nationwide fall prevention initiative called Stopping Elderly Accidents, Deaths, and Injuries (STEADI) was created to guide health care providers in implementing evidence-based clinical care guidelines in the growing older adult population.

To reduce falls, the American Geriatrics Society/ British Geriatrics Society (AGS/BGS) created clinical practice guidelines for fall prevention [4]. The Centers for Disease Control and Prevention (CDC) adopted AGS/BGS's clinical practice guidelines and used them to develop a toolkit for use in primary care. The STEADI initiative has three core elements: 1) screening patients for fall risk, 2) assessing modifiable fall risk factors, and 3) offering interventions to reduce fall risk [3]. Modifiable fall risk factors include functional measures of gait, muscle strength, balance, and vitamin D [5].

Nutrition factors such as diet quality, protein intake, dairy intake, and vitamin D intake can contribute to the improvement of functional measures including muscle strength [6-8], lower body strength [7,9], balance [9], mobility [9], and physical performance [9,10] and reduction in fall risks $[11,12]$. Inadequate protein intake $(0.8 \mathrm{~g} / \mathrm{kg} / \mathrm{day})$ or low vitamin $\mathrm{D}$ level can contribute to the loss of muscle mass and strength [5,6], which have been associated with increased fall risk [15]. This study aims to determine if there is a relationship between nutrition risk assessed by the Dietary Screening Tool (DST) and functional measures and fall risk among older adults participating in a fall-prevention intervention. 


\section{CHAPTER 2: LITERATURE REVIEW}

The primary purpose of this narrative literature review is to detail what is known about the association between diet quality and functional measures and fall risk among communitydwelling older adults.

\section{Fall Risk in Older Adults}

A fall is defined as any unintended non-medical event resulting in a person finding themselves on a lower supporting surface [5]. Fall risk is potentially modifiable; thus, it can be prevented. Modifiable fall risk factors include physical inactivity, lower extremity weakness, poor balance, improper assistive device use, taking medications, orthostatic hypotension, vitamin D deficiency, poor vision care, fear of falling, depression, social isolation, and home hazards [5]. Unmodifiable risk factors include advanced age (> 65 years old), history of falls, being female, polypharmacy, low vision, poor sensation in feet/legs, ethnicity (non-Hispanic whites and Asian), chronic diseases, and low cognition [5].

Health care providers (i.e., physicians, nurse practitioners, physician assistants, physical therapists, or nurses) evaluate the modifiable fall risk factors and then may recommend an evidence-based fall-prevention program such as Tai Ji Quan: Moving for Better Balance ${ }^{\circledR}[5]$. Fall prevention programs generally aim to reduce fall risk by increasing physical activities aimed at improving lower extremity weakness and balance problems [5]. A randomized clinical trial applied a Tai Ji Quan intervention in older adults $(n=670)$ with a history of falls or impaired mobility [16]. After six months, falls were reduced by $31 \%$ for the older adults who participated in the program [16]. Other interventions include reducing medications linked to falls, improving home safety, referring patients to an eye specialist in hopes of improving vision, and optimizing other fall conditions [3].

There are various fall screening tools that can be used in the geriatric population. In 2011, the AGS/BGS conducted a literature search that included meta-analyses, systematic 
literature reviews, randomized controlled trials (RCTs), controlled before-and-after studies, and cohort studies to provide recommendations for fall prevention [4]. The CDC adopted clinical guidelines from the AGS/BGS to develop and created STEADI with an algorithm [3]. The CDC established the STEADI initiative to implement the AGS/BGS fall-prevention guidelines [4].

The STEADI initiative suggests using one of two methods to screen for falls risk, a 12question Stay Independent questionnaire or three key questions about fear of falling and fall history. In those who screen at risk for falls, an assessment is completed to identify modifiable risk factors. Fall risk assessments usually include measures of balance (i.e., the Mini Balance Evaluation Systems Test, Berg Balance Scale) and gait (i.e., Tinetti Performance Oriented Mobility Assessment, Timed Up and Go test (TUG), and 10-m Walk Test) [5]. The STEADI initiative includes an assessment to identify the mobility problems [5] and other functional measures such as the 30-Second Chair Stand test for muscle strength and the 4-Stage Balance test for measuring balance.

The Internal Medicine and Geriatrics Clinic at Oregon Health \& Science University implemented and incorporated STEADI in a primary care setting to help primary care providers identify fall risk [17]. Seven hundred seventy-three patients were screened over six months, and 109 patients received the interventions related to gait, vision, feet, orthostatic blood pressure, vitamin D, and medications [17]. Data from the National and Health Aging Trends Study attempted to operationalize and validate the STEADI fall risk among older adults $(n=7,392)[18]$. Participants classified as having fall risk had greater odds of falling $(2.62,95 \%$ CI: $2.29,2.99$, and 4.76, 95\% CI: 3.51, 6.47) [18]. Thus, STEADI was identified as a validated tool for identifying fall risk in older adults [18].

\section{Diet Quality and Fall Risk}

Lower diet quality indicated the loss of muscle mass or weakened muscle strength [9], 
which can lead to increased fall risk [19]. Higher diet quality can lead to decreased fall risk. A study of Korean adults aged $\geq 65$ years $(n=3,675)$, higher diet quality measured using the Korean Healthy Diet Eating Index, and the Alternate Mediterranean Diet, was associated with higher grip strength in both men and women [20]. Multivariate odds ratios showed that higher diet quality had a significantly lower odds of low grip strength (men $<28.6 \mathrm{~kg}$ and women $<$ $16.5 \mathrm{~kg})(\mathrm{p}<0.05)[20]$.

Grip strength is the indicator of muscle strength [9]. In a review of literature on the relationship between diet quality and functional measures, eleven studies assessed participants for grip strength, and fifteen studies assessed other functional measures (i.e., gait speed, TUG, and balance) [9]. Among the eleven studies examining muscle strength, there is weak evidence of a positive association between diet quality and muscle strength. On the other hand, there is evidence of a positive association between other functional measures (i.e., gait speed, TUG, and balance) and diet quality [9].

In a study of community-dwelling older adults $(\mathrm{n}=171)$ without walking difficulties, associations between diet quality, fall risk, physical function, physical activity, and body composition were examined. The subjects reported falls that had occurred over the previous twelve months [21]. Diet quality was assessed using the Health Diet Indicator (HDI) and the Healthy Eating Index (HEI). Fall risk was assessed by the Activities-specific Balance Confidence and Falls Efficacy Scale - International (FES-I). The results showed a weak positive association between diet and fall risk assessed using the Activities-specific Balance Confidence in only the male participants $(\mathrm{r}=0.26, \mathrm{p}=0.03)$ and between diet measured via the HDI and FES-I $(p=0.04)$ in only the male participants. There was a weak negative association between HDI and body mass index (BMI) $(r=-0.21, p=0.04)$ in the female participants. As there were significant findings when the participants were differentiated by gender, the findings of associations between diet quality and fall risk were gender-specific. 
Physical inactivity is identified as a fall risk factor; thus, the United States Preventive Services Task Force (USPSTF) recommends exercise interventions for fall prevention [22]. In a cross-sectional study, older adults $(n=819)$ at least 85 years old were examined to determine the association between dietary intake and physical activity [23]. Diet was assessed using the Elderly Diet Index score, and physical activity was assessed using the International Physical Activity Questionnaire, which asked the time and number of days spent engaging in physical activity of light, moderate, and vigorous intensity. The scores of the Elderly Diet Index are based on intakes of meat, fish and seafood, vegetables, cereals, fruits, legumes, and olive oil. The higher scores in the Elderly Diet Index indicated better diet quality. Higher Elderly Diet Index scores were associated with physical activity of at least $150 \mathrm{~min}$ of moderate-intensity aerobic physical activity or at least 75 minutes of vigorous-intensity aerobic physical activity throughout the week ( $\mathrm{OR}=4.99 ; 95 \%$ CI 3.20 to 7.70). Elderly participants who had a higher diet score had about five times the odds of doing 75 minutes of vigorous exercise during the week than those with a lower diet score [23].

\section{Protein Intake and Fall Risk}

Inadequate protein intake $(<0.8 \mathrm{~g} / \mathrm{kg} /$ day $)$ was associated with the loss of muscle mass and strength $[5,6]$, which can lead to increased fall risk [13,14]. Studies assessing associations between protein intake and grip strength show conflicting results $[7,8,24]$. Two studies found that women with higher protein intake had higher grip strength. In a study $(n=4,123)$ that utilized the National Health and Nutrition Examination Survey, the associations between protein intake and grip strength among adults aged 51 years or older were assessed [24]. The statistical model analysis was adjusted for age, race/ethnicity, smoking status, self-reported health status, energy-adjusted protein intake, and physical activity [24]. A positive association was found between grip strength and protein intake in women with protein intakes in third and fourth quartiles (mean intakes of 71.4 and $104.1 \mathrm{~g}$, respectively) compared to the lowest 
quartile $(33.6 \mathrm{~g})(\mathrm{p}<0.05)$ [24]. In a cross-sectional study $(\mathrm{n}=554)$ on women aged 65 years or older, researchers examined the associations between protein intake and the functional measures handgrip strength and gait speed [7]. In the linear and logistic regression models, women with higher protein intake ( $\geq 1.2 \mathrm{~g} / \mathrm{kg}$ body weight) had better performance in handgrip strength $(\mathrm{p}=0.001)$ and gait speed $(\mathrm{p}=0.005)$ compared to women with lower protein intake $(0.81-1.19 \mathrm{~g} / \mathrm{kg}$ body weight and $\leq 0.8 \mathrm{~g} / \mathrm{kg}$ body weight $)$ at baseline. However, the regression model, which controlled fat mass, showed no significance in associations between protein intake and grip strength or gait speed [7].

In the Framingham Offspring Cohort of older adults $(n=1,746)$, protein intake greater than 63 g per day, measured by the Willet Food Frequency Questionnaire, was protective against the loss of grip strength per year $(\mathrm{p}<0.05)$ [8]. In a cross-sectional study of communitydwelling older adults $(n=140)$, researchers examined the associations between protein intake measured by two 24-hour recalls and functional measures, including the Five Times-Sit to Stand (FTSTS) test, gait speed, and physical activity. The study found no associations of total protein intake with gait speed, FTSTS, and handgrip strength based on the adjusted linear regression models [25].

Studies examining associations between protein and fall risk were also reviewed. Another Framingham study $(\mathrm{n}=807)$ investigated the association between dietary protein intake and the rate of falls [26]. Protein intake was analyzed as tertiles, which were regressed on total energy intake. The result showed that protein intake was not protective against the odds of falls (p-value range: $0.12-0.50)$. Total protein intake was associated only when tertile two was compared to tertile one. (RR tertile 2: $0.79,95 \%$ CI: $0.55-1.13$, RR tertile $1: 0.69,95 \%$ CI: 0.48-0.99). Participants with higher protein intake had a $10 \%$ decreased fall risk. However, the association between higher protein intake, total and animal protein intake, and lower odds of falls was significant among participants with a weight loss of at least 5\% (RR tertile 2: 0.46, 
95\% CI: $0.22-0.93$, RR tertile 1: $0.53,95 \%$ CI: $0.30-0.93$, p-value=0.03). Higher protein intake had a $10 \%$ lower risk of falls among the participants with weight loss [26].

The relationship between protein intake and falls among older women was examined. The diets of older women $(n=4,369)$ were assessed using the Block Food Frequency Questionnaire and self-reported falls [27]. Women with higher protein intake $(\geq 0.8 \mathrm{~g} / \mathrm{kg})$ had more falls in the past four months than women with lower protein $(<0.8 \mathrm{~g} / \mathrm{kg})$ intake (falls: 935 vs. $519, \mathrm{p}=0.043)$. Increasing $1 \mathrm{~g} / \mathrm{kg}(50 \mathrm{~g}$ per day) of dietary protein was significantly associated with an increased risk of falls (OR: 1.35, 95\% CI: 1.15-1.59, p <0.001). In other words, for every $50 \mathrm{~g}$ increase in protein intake per day, there were $22 \%$ increased odds of falling [27]. This finding is in agreement with another study, in which having a high intake in animal protein over vegetable protein was associated with an increased rate of bone loss and the risk of fracture [28], while increased bone loss can subsequently lead to increased fall risk.

In a Spanish community-dwelling cohort of adults aged 60 years or older $(n=2,464)$, there were no associations between protein intake and fall risk $(\mathrm{p}=0.14)$, but negative associations were found among participants (6.6\%) with unintentional weight loss where participants with unintentional weight loss had three times higher fall risk compared to the participants without unintentional weight loss $(p=0.01)$ [29]. In a short-term intervention study of malnourished older adults $(\mathrm{n}=210)$ in an inpatient hospital setting, the effects of protein and vitamin D on falls were examined [30]. Participants were classified as malnourished if BMI was $20.0 \mathrm{~kg} / \mathrm{m}^{2}$ or less if they had $5 \%$ or more of self-reported unintentional weight loss in the previous month, or $10 \%$ or more of self-reported unintentional weight loss in the previous six months. The participants were given energy- and protein-enriched diets with approximately $250 \mathrm{kcal}$ and $10 \mathrm{~g}$ of protein, two additional servings per day of an ONS (Nutri-drink), which provided $600 \mathrm{kcal}, 24 \mathrm{~g}$ protein, $176 \mathrm{IU}$ vitamin $\mathrm{D}_{3}$ and $364 \mathrm{mg}$ calcium for a total of six weeks [30]. They also had a combined $400 \mathrm{IU}$ of vitamin $\mathrm{D}_{3}$ and $500 \mathrm{mg}$ of calcium supplements per 
day. Dietary intake was calculated via a nutritional analysis software application and the Dutch Food Composition Table. The inpatient participants were asked to report any fall incidents that occurred in the hospital. Ten percent of the intervention group and 23\% of the control group had at least one fall incident (hazard ratio $=0.41,95 \%$ confidence interval $(\mathrm{CI})=0.19-0.86$, $\mathrm{p}=0.02)$. In conclusion, the short nutritional intervention of malnourished older adults led to reduced numbers of fall incidents [30]. The Framingham study showed that higher protein intake was associated with a reduced risk of falls [26]. On the other hand, two studies showed no association between protein intake and falls, and two studies demonstrated higher protein intake related to the risk of falling.

\section{Vitamin D and Fall Risk}

Sufficient vitamin D status has been associated with increased muscle mass and strength [31]. Stopping Elderly Accidents, Deaths, and Injuries (STEADI) recommends giving vitamin D to older adults with vitamin D deficiencies based on the systematic review about the effects of vitamin D on falls [32]. The clinical review evaluated 26 studies with participants given a vitamin $\mathrm{D}$ supplement. There was a significant reduction in fall risk in participants who were supplemented with vitamin D (OR who were at risk of suffering at least one fall, 0.86 ; 95\% CI, 0.77-0.96).

High dosages of vitamin D can increase the number of falls according to a 1-year, randomized, prospective, placebo-controlled clinical trial [32]. The participants of that clinical trial were older Caucasian and African American postmenopausal women with an age range of 57 to 90 years old. Baseline fall history and quarterly fall events were self-reported. Participants were randomly assigned to one of seven vitamin D dose groups (Vitamin $\mathrm{D}_{3} 400-$, , 800-, 1,600-, 2,400-, 3,200-, 4,000-, and 4,800-IU) or the placebo group. The participants taking dosages of $1,600,2,400$, or 3,200 IU had decreased falls, and participants with low dosages showed no decrease in fall incidences $(\mathrm{p}=0.020)$. The participants with a high vitamin $\mathrm{D}$ dosages also did 
not show a reduction in falls compared to the placebo group $(\mathrm{p}=0.55)$ [33]. The subgroup with a fall history demonstrated fall rates $68 \%$ on a low dose, $27 \%$ on a medium dose, and $100 \%$ on a high Vitamin D dose [33].

In 2012, the USPSTF recommended vitamin D supplementation to community-dwelling at risk for falls [34]. In 2018, the USPSTF conducted a review of the literature and found that data was not sufficient to continue to recommend vitamin D supplementation to prevent falls [22]. Thus, the USPSTF updated its recommendation to say that vitamin D is not recommended for fall prevention in community-dwelling older adults [22]. The STEADI initiative includes recommendations for vitamin D when appropriate [32].

\section{Dietary Screening Tool (DST)}

The DST is a 24-question dietary assessment tool validated for use in middle-aged [35] and older adults [36,37]. It is designed to characterize the overall dietary patterns of older adults into three categories based on nutrition risk [36]. Higher scores on the DST indicate greater adherence to the US Department of Agriculture's 2005 Dietary Guideline [36]. The DST consists of food behavior questions and can be completed within 10 minutes. The studies which used the DST reported that older adults had no difficulty with the completion of the DST $[36,37]$. The comparison of nutrition risk with the DST based on the Dietary References Intakes showed an $83 \%$ sensitivity, $75 \%$ specificity, and $75 \%$ positive predictive value [37]. Thus, the DST was selected and utilized by our study to evaluate the diet quality and nutrition risk of the community-dwelling older adults.

The total DST scores can range from 0 to 105, and higher points indicate higher diet quality. The groups are categorized as "at-risk" $(<60)$, "possible-risk" (60-75), and "not-atrisk" groups (>75) [39]. The proportion of participants in each nutrition risk group has varied between studies. In most of the studies, the "possible-risk" group had the highest percentage of participants, followed by the "at-risk" group and then the "not-at-risk" group. In a study of 
Supplemental Nutrition Assistance Program participants $(\mathrm{n}=275), 43 \%$ were "at-nutrition risk", $45 \%$ were "at-possible-risk," and $12 \%$ were "not-at-risk" [38]. In a cross-sectional study of participants who attended community-based nutrition education and physical activity program $(n=204), 28 \%$ were "at-risk," 46\% were at "possible-risk," and 26\% were "not-at-risk" based on their total DST scores [39]. When DST is used in the middle-aged population $(n=87)$, a larger proportion was at nutrition risk (64.6\%) than at "possible-risk" or "not-at-risk" $(35.4 \%)$ compared to other studies in older adult populations [35].

Other studies that used DST showed nutrition risk associations. In a study of community-dwelling older adults $(n=203)$, nutrition risk was determined by the DST; $28 \%$ were "not-at-risk" $46 \%$ were at "possible-risk," and $26 \%$ were "at-risk." The "at-risk" group had higher scores on the GDS than the "possible-risk" and "not-at-risk" groups. For age and BMI, the "at-risk" group was not statistically different from the "possible-risk" and "not-atrisk" groups. In a Geisinger Rural Aging study $(n=122)$ of the oldest old participants (aged $\geq 80$ years), $49 \%$ were "at-risk," $41 \%$ were at "possible-risk," and 10\% were "not-at-risk" [37]. There were no statistical differences in age, BMI, or depression among these groups [37]. Another Geisinger Rural Aging study $(n=4,009)$ underweight participants had lower DST scores than normal-weight participants, but no differences were detected in overweight or obese participants [40].

\section{Conclusion}

Figure 1 summarizes the relationship of diet (i.e., diet quality, protein intake, and vitamin D intake) with functional measures, physical activity, and falls from this literature review. Diet quality was associated with muscle mass [9], grip strength [9,20], lower body strength [9], balance [9], mobility [9], physical performance [9], and physical activity [23]. Also, diet quality was negatively correlated with fall risk [41]. Protein intake was associated with muscle mass [42], and grip strength [43]. A cross-sectional study did not find an 
association between protein intake and other functional measures (FTSTS, gait speed, and TUG) [25]. Another Framingham Cohort study found that high protein intake was associated with decreased fall risk [26]. Dairy intakes were associated with muscle mass and grip strength [44]. Sufficient vitamin D status has been associated with increased muscle mass and strength [31]. Muscle mass [19], grip strength [19,45], lower body strength [46], balance [47], mobility [48], physical performance [49,50], physical activity [51] have all been associated with fall risk. Thus, the aim of this study was to investigate the associations between nutrition factors and fall risk to contribute to the current literature.

\begin{tabular}{|c|c|c|}
\hline Diet & Functional Measures & Fall Outcomes \\
\hline $\begin{array}{l}\text { Protein } \\
\text { Dairy }\end{array}$ & \begin{tabular}{|c} 
Muscle Mass \\
Muscle Strength \\
(Handgrip strength) \\
Lower Body Strength \\
(Five Times Sit-to Stand \\
test) \\
Balance \\
(Four-Square Step test) \\
Mobility \\
(Timed Up and Go test) \\
Physical Performance \\
(Gait Speed) \\
Physical Activity
\end{tabular} & Falls \\
\hline
\end{tabular}

Figure 1. Relationship of Diet with Functional Measures, Physical Activity, and Falls 


\section{CHAPTER 3: METHODS}

\section{Study Design and Participants}

In this cross-sectional study, baseline data were analyzed from a sample $(n=192)$ of community-living older adults participating in an evidence-based, community-delivered, fallprevention intervention for which dietary data were available. The primary purpose of the fall prevention intervention was to evaluate the adoption of an evidence-based Tai Chi exercise program by rural faith-based organizations (FBO) in West Virginia [52]. The Institutional Review Board at West Virginia University approved the study protocol, and all of the participants provided written informed consent. Results and recruitment details are described elsewhere [52]. Briefly, adults 55 years of age and older were recruited from 20 FBOs in West Virginia using brochures, press releases, newspaper articles, word-of-mouth, and snowball sampling [52]. The flow of participants for this study is provided in Figure 2.

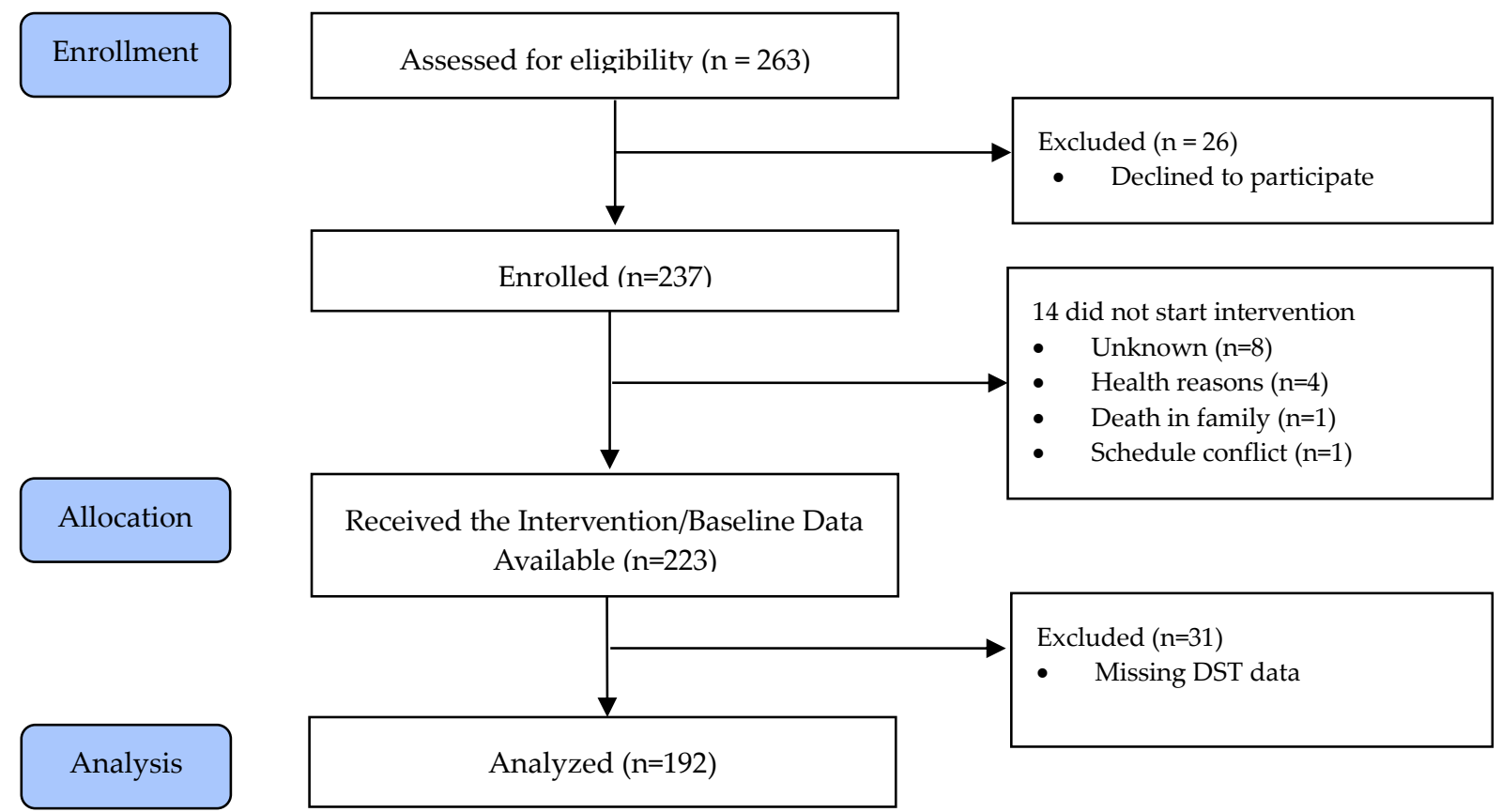

Figure 2. Recruitment Flow Chart 


\section{Outcome Measures}

\section{Diet Assessment}

Diet was assessed using the DST, a 25-item questionnaire validated for use among rural older adults [39] and middle-aged adults in West Virginia [35]. The diet factors analyzed for this study included overall diet quality, nutrition risk, protein intake, and multivitamin use as a proxy measure for vitamin D intake. To obtain an overall diet quality score, the DST was scored based on the published algorithm [36]. Subcomponent scores were assigned to seven food categories. Maximum points were given for higher intakes of whole fruit and juices (15 points); vegetables (15 points); total and whole grains (15 points); lean proteins (10 points); dairy products (10 points); and lower intakes of added fats, sugars, and sweets; (25 points) and processed meats (10 points). Five additional points were added if the individual took a multivitamin and mineral supplement. The scores from each food category were summed for a total diet quality score, which could range from 0 to 105 points with higher points indicating better adherence to a healthy dietary pattern.

Total DST scores were then categorized into three nutrition risk categories based on the cut-points in the validation study: "at-risk $(<60)$ ", "possible-risk $(60-75)$ ", and "not-at-risk (>75)" [39]. For analysis of protein intake, the DST scores for processed meats were inversely calculated to assign higher scores to higher intakes. This calculation differs from how the processed meats were calculated for determining total DST or diet quality scores. For calculating diet quality, higher intakes of processed meats yield lower scores due to their sodium content. Total protein scores ranging from 0-30 points were determined by summing lean proteins, dairy products, and processed meats. The use of a multivitamin and mineral supplement was used as a proxy measure for vitamin D intake.

\section{Functional Measures and Physical Activity Assessment}

Four fall-related functional measures were assessed: muscle strength, gait speed, 
balance, and mobility. Muscle strength was assessed by handgrip strength [53] and lower extremity muscle strength [46]. Handgrip strength was measured using a hydraulic hand dynamometer (Jamar ${ }^{\mathrm{TM}}$, Preston, Jackson, Missouri). Measures (kg) were taken in triplicate per hand, and the maximum value was used for analysis. Values $\leq 25.8 \mathrm{~kg}$ for men and $\leq 17.4$ $\mathrm{kg}$ for women indicated lower muscle strength [54]. Lower body muscle strength was assessed using the FTSTS [46]. The FTSTS test measures the number of seconds it takes for a person to stand from a seated position five-times. Participants with values $>15$ seconds were classified as having a greater risk for one or more future falls [3]. Gait speed was measured by the 5Meter Walk Test (meters/second) were performed two trials at a normal comfortable pace [53]. Average values $<1 \mathrm{~m} / \mathrm{s}$ indicated greater risk of one or more future falls $[55,56]$. Balance was measured (seconds) using the Four-Square Step Test (FSST). Two PVC pipes were tied together in the shape of a cross. Participants were timed as they stepped over the pipes in a clockwise and then a counterclockwise direction without touching the pipes. The test was performed twice, and the lowest (i.e., best) value was used for analysis. Values $>15$ seconds were classified as having a greater risk of being a multiple faller [57]. The TUG measured the length of time (seconds) it took for a person to stand, walk 3 meters, turn around, walk back to the chair, and sit down. [48]. Values greater than or equal to 12 seconds a greater risk of one or more future falls [3].

Physical activity was assessed using four questions from the 2006 National Health Interview Survey (NHIS): 1) how many days per week do you do vigorous leisure-time physical activities for at least 10 minutes that cause heavy sweating or large increases in breathing or heart rate?, 2) about how long do you do these vigorous leisure-time activities each day?, 3) how many days per week do you do light or moderate leisure-time physical activities for at least 10 minutes that cause only light sweating or a slight to moderate increase in breathing or heart rate?, and 4) about how long do you do these light, moderate leisure-time 
activities each day? [58]. Participants reported the number of minutes per day for two levels of activity: light/moderate and vigorous. Total activity time was calculated as [minutes of light/moderate activities $+(2 \mathrm{x}$ the minutes of vigorous activities $)]$.

\section{Fall Risk Assessment}

Fall risk was dichotomized into two risk groups, "not at fall risk" or "at fall risk," by applying collected data to the STEADI algorithm, as shown in Figure 3. Participants were screened using the following three questions: 'Have you fallen in the past year?', 'Are you worried about falling?' and 'Do you feel unsafe or unsteady while walking?'.

Participants were classified into an "at fall risk" group if they answered yes to any one of the three questions as per the STEADI instructions.

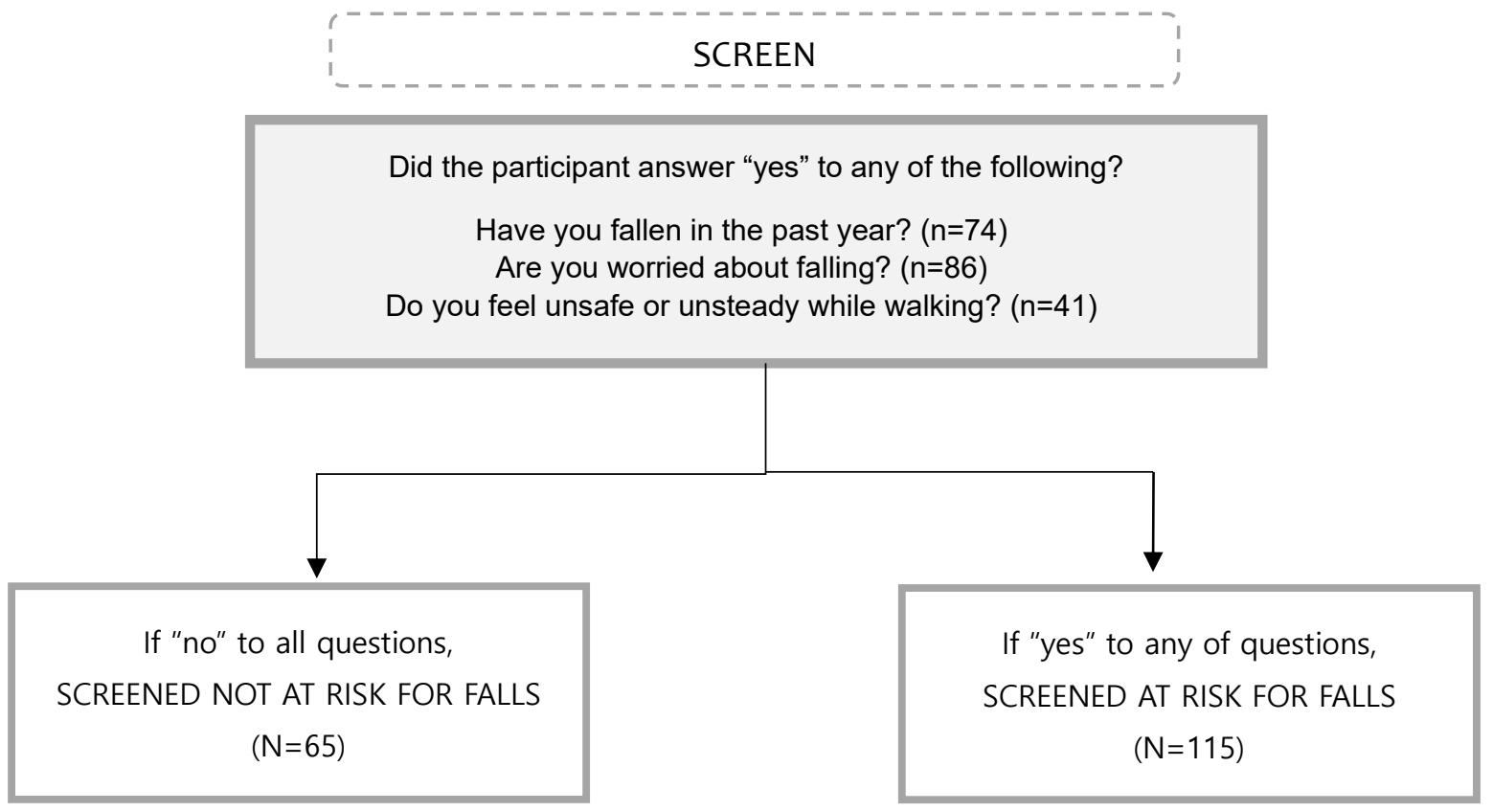

Figure 3. Stopping Elderly Accidents, Deaths, and Injuries (STEADI) Algorithm for Determining Fall Risk Categories: "not at fall risk" and "“at fall risk." After answering all three questions, the participants were placed in either STEADI fall risk categories. 


\section{Potential Confounding Variables}

Participants reported socio-demographic data via a questionnaire: age, gender, race/ethnicity, education level, and income level. Participants were asked via the baseline questionnaires regarding health concerns such as taking four or more medications per day, arthritis, diabetes, Parkinson's disease, and incontinence. Those health concerns were considered as the potential confounding variables.

Height was measured in inches using the Seca 213 stadiometer. Weight was measured in pounds using a Tanita BC-350 scale. BMI was calculated as weight (lbs) / height ${ }^{2}$ (inches) x 703 [59] and classified using National Heart, Lung, and Blood Institute classifications [60]. Waist circumference was measured using a non-stretchable tape in centimeters $(\mathrm{cm})$ [58]. Values $>102 \mathrm{~cm}$ for men and $>88 \mathrm{~cm}$ for women were categorized as 'at risk' for having type 2 diabetes, hypertension, and cardiovascular disease using National Heart, Lung, and Blood Institute (NIH) classifications [60].

Depression was assessed using the GDS, which has been validated for use in older adults [61]. Participants answered fifteen questions, and one point was assigned to each 'yes' response. Scores were summed to attain a total score ranging from 0 to 15 and categorized participants into one of the following categories: normal (0-5 points), suggests depression (69) and indicates depression (10-15) [61]. Cognitive impairment was assessed using the SixItem Screener (SIS) tool [62]. Participants answered six questions consisting of a three-item recall (i.e., apple, table, penny) and a three-item temporal orientation (i.e., day of the week, month, year). One point was assigned to each correct response [63]. Total possible cognition scores ranged from $0-6$ with higher scores indicating better cognition [63].

\section{Analyses}

Associations of sociodemographic and health-related characteristics with the DST were estimated using the Chi-square test for categorical variables, t-test for normalized 
continuous variables, and Wilcoxon test for unnormalized continuous variables. Associations of diet quality, protein intake, vitamin D intake, DST nutrition risk categories, fall risk factors, functional measures, and physical activity with STEADI were estimated using Chi-square tests for categorical variables and t-test for normalized continuous variables and Wilcoxon test for unnormalized continuous variables. Continuous variables are presented as means \pm standard deviations, and categorical variables are presented as counts with percentages. Correlation of DST total scores and protein score with fall risk factors was determined using Spearman's correlation test for not normally distributed variables. Multivariate analysis was conducted by using the nominal logistic regression model utilizing covariates determined in previous bivariate analyses. The risk of fall was predicted, and odds ratio of "fall risk" to "no fall risk" were determined while adjusting for the covariates. Data were analyzed using JMP software (JMP®, Version Pro 14.0, Copyright @2018). Significance criterion alpha for all tests was 0.05, and a statistical trend was declared when $\mathrm{p}<0.1$. 


\section{CHAPTER 4: RESULTS}

\section{Participant Characteristics}

Table 1 shows the baseline characteristics of the study sample $(n=192)$ by DST categories. On average, the participants were $70.9 \pm 9.0$ years old. They were predominantly female $(81.8 \%)$ and non-Hispanic White $(85.9 \%)$. The majority $(92.1 \%)$ had at least a high school education, and $41.7 \%$ had an annual income between $\$ 25,000$ and $\$ 49,999$. The average BMI was $30.47 \pm 6.54$, and a majority $(65.8 \%)$ had an elevated waist circumference. Ninetyone percent were normal in the GDS category.

Table 1. Baseline Characteristics among Participants $(\mathrm{N}=192)$ of a Falls Prevention Intervention by DST Nutrition Risk Category

\begin{tabular}{|c|c|c|c|c|c|}
\hline & Total $(n=192)$ & $\begin{array}{l}\text { Not-at-Risk } \\
\quad(n=28)\end{array}$ & $\begin{array}{c}\text { Possible } \\
\text { risk }(n=87)\end{array}$ & $\begin{array}{c}\text { At-risk } \\
(n=77)\end{array}$ & $p$-value ${ }^{1}$ \\
\hline \multicolumn{6}{|l|}{ Sociodemographic Variable } \\
\hline Age & $70.86 \pm 9.0$ & $72.27 \pm 9.37$ & $71.05 \pm 8.81$ & $70.12 \pm 9.13$ & $\mathrm{p}=0.52$ \\
\hline \multicolumn{6}{|l|}{ Gender } \\
\hline Male & $35(18.2 \%)$ & $4(14.3 \%)$ & $15(17.2 \%)$ & $16(20.8 \%)$ & \multirow[t]{2}{*}{$\mathrm{p}=0.71$} \\
\hline Female & $157(81.8 \%)$ & $24(85.7 \%)$ & $72(82.8 \%)$ & $61(79.2 \%)$ & \\
\hline Race/Ethnicity: Non-Hispanic & $165(85.9 \%)$ & $24(85.7 \%)$ & $75(86.2 \%)$ & $66(85.7 \%)$ & $\mathrm{p}=0.61$ \\
\hline \multicolumn{6}{|l|}{ Education level } \\
\hline Less than high school & $15(7.9 \%)$ & 0 & $7(8.1 \%)$ & $8(10.5 \%)$ & \multirow{3}{*}{$\mathrm{p}=0.014$} \\
\hline High school completed & $81(42.6 \%)$ & $7(25.9 \%)$ & $34(25.9 \%)$ & $40(52.6 \%)$ & \\
\hline More than high school & $94(49.5 \%)$ & $20(74.1 \%)$ & $46(52.9 \%)$ & $28(36.8 \%)$ & \\
\hline \multicolumn{6}{|l|}{ Income } \\
\hline$>\$ 25,000$ & $43(22.4 \%)$ & $4(14.3 \%)$ & $15(17.2 \%)$ & $24(31.2 \%)$ & \multirow{4}{*}{$\mathrm{p}=0.33$} \\
\hline$\$ 25,000$ to $\$ 49,999$ & $80(41.7 \%)$ & $13(4.64 \%)$ & $38(43.7 \%)$ & $29(37.7 \%)$ & \\
\hline$\geq \$ 50,000$ & $49(25.5 \%)$ & $7(25.0 \%)$ & $26(29.9 \%)$ & $16(20.8 \%)$ & \\
\hline Did not respond & $20(10.4 \%)$ & $4(14.3 \%)$ & $8(9.2 \%)$ & $8(10.4 \%)$ & \\
\hline \multicolumn{6}{|l|}{$\mathrm{BMI}^{2}$} \\
\hline Normal weight (18.5-24.9) & $35(18.6 \%)$ & $7(25.9 \%)$ & $16(18.8 \%)$ & $12(15.8 \%)$ & \multirow{3}{*}{$\mathrm{p}=0.69$} \\
\hline Overweight (25.0-29.9) & $64(34.0 \%)$ & $7(25.9 \%)$ & $32(37.7 \%)$ & $25(32.9 \%)$ & \\
\hline Obesity $\left(\geq 30 \mathrm{~kg} / \mathrm{m}^{2}\right)$ & $88(46.8 \%)$ & $13(48.2 \%)$ & $36(42.3 \%)$ & $39(51.32 \%)$ & \\
\hline WC, 'At Risk' 3 & $123(65.8 \%)$ & $18(66.7 \%)$ & $50(59.5 \%)$ & $55(72.4 \%)$ & $\mathrm{p}=0.23$ \\
\hline Cognition (0-6) & $5.73 \pm 0.63$ & $5.82 \pm 0.12$ & $5.80 \pm 0.07$ & $5.61 \pm 0.07$ & $\mathrm{p}=0.11$ \\
\hline Depression & $2.10 \pm 2.2$ & $1.57 \pm 1.89$ & $1.78 \pm 0.23$ & $2.66 \pm 0.25$ & $\mathrm{p}=0.014$ \\
\hline \multicolumn{6}{|c|}{$\begin{array}{l}\text { Values are mean } \pm \text { SD or } n(\%) . N=192 \text { except for education level }(\mathrm{n}=190) \text { and depression }(\mathrm{n}=191) \text {. } \\
\text { Abbreviations: BMI }=\text { Body Mass Index; DST = Dietary Screening Tool; FTSTS = Five Times Sit-to-Stand; } \\
\text { FSST = the Four-Square Step Test; TUG = Timed Up and Go test; STEADI = Stopping Elderly Accidents, } \\
\text { Deaths \& Injuries. }{ }^{1} \text { Significance criterion alpha for all tests was } 0.05 \text {; statistical trend was declared when } \\
\mathrm{p}<0.1 \text { with t-test for normalized continuous variables and Wilcoxon test for unnormalized continuous variables } \\
\text { and Chi-square test for the categorical variables. }{ }^{2} \text { One participant was classified as underweight. 'At risk' } \\
\text { waist circumference } \geq 102 \mathrm{~cm} \text { in men or } \geq 88 \mathrm{~cm} \text { in women. }\end{array}$} \\
\hline
\end{tabular}




\section{Diet Assessment}

\section{Diet quality}

Participants had diet quality scores from the DST ranging from 24 to 90 out of 105 points and averaged $61.70 \pm 12.34$, which is at the high end of the "possible-risk" category. Figure 4 shows the mean score percentage of DST subgroups, protein score, and total DST score for "not at fall risk," "at fall risk," and total participants. Participants in the "not at risk" category had a higher percentage in whole fruit and juice, total and whole grains, added fats, sugars, and sweets, and dairy products than participants in the "at fall risk" category. However, there was no significant association between "not at fall risk" and "at fall risk" in terms of the mean score percentage of all DST subgroups.

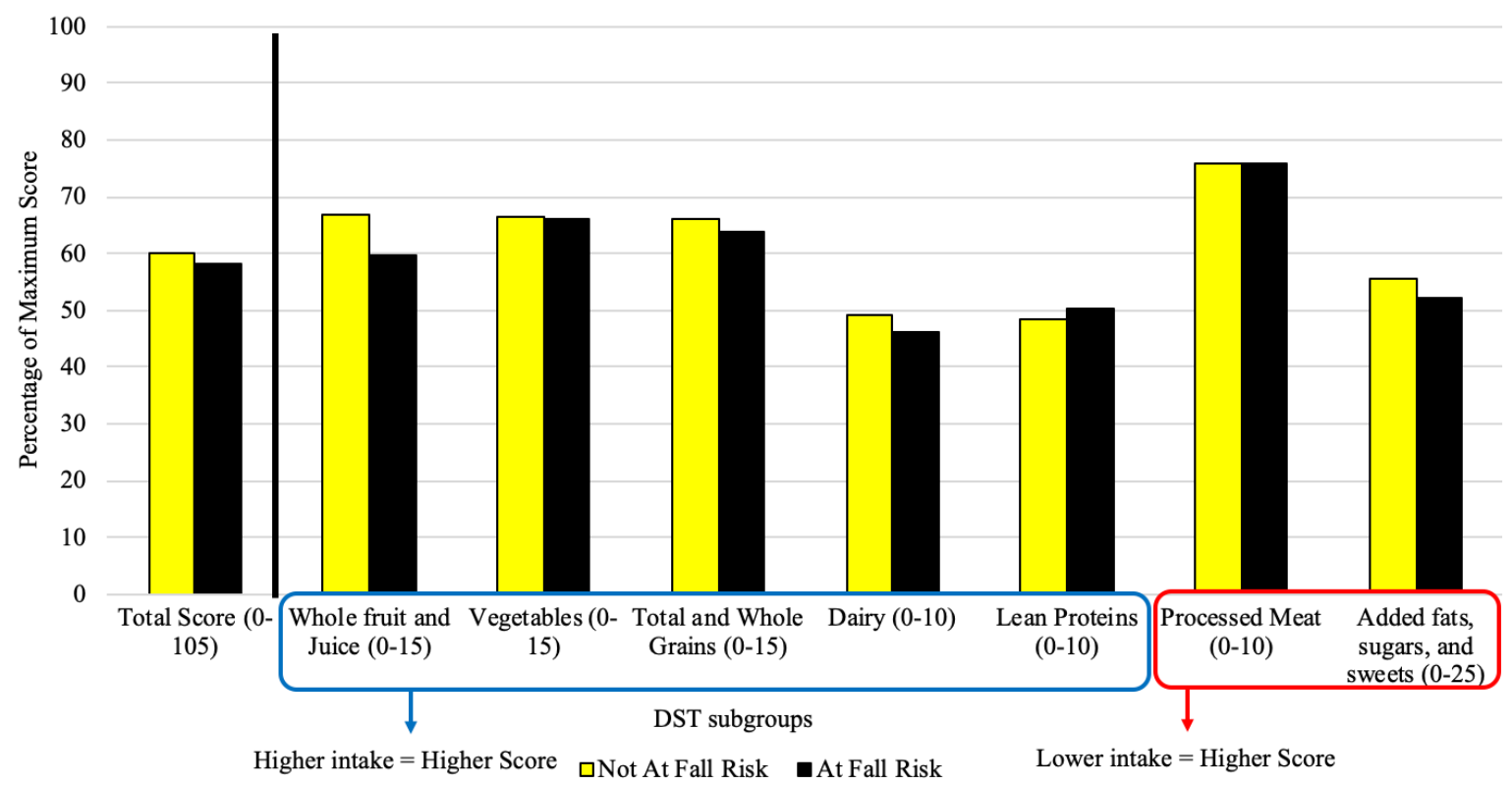

Figure 4. Dietary Intakes of STEADI Categories by DST Subgroups. The mean percentages of dietary intake ranged from $0-100 \%$ per STEADI categories ("not at fall risk' and 'at fall risk') for all DST subgroups. The percentage of the DST subgroup was calculated in each fall risk category as [participants' score for DST subgroup/ Maximal possible subgroup score] $\mathrm{x}$ 100. The mean is calculated from the percentage of DST subgroups within each STEADI category. Wilcoxon test was used to test the significance between STEADI categories. 


\section{Nutrition risk}

Based on the DST scores, $39.5 \%$ of participants were classified as nutritionally being "at-risk," 46.1\% were at "possible-risk," and 14.4\% were "not-at-risk". There were no differences in rates of nutrition risk between men and women $(59.26 \pm 2.08 v s .69 .25 \pm 0.98$, p $=0.12$ ). Protein scores ranged from 0 to 24 points and averaged $13.13 \pm 4.71$ out of a possible score of 30. Men, on average, had higher protein intakes than women $(14.80 \pm 0.79$ vs. 12.76 $\pm 0.37, \mathrm{p}=0.02)$.

Seventy-nine participants $(41.2 \%)$ indicated they used a multivitamin and mineral supplement. Numerically, more women than men took a supplement, but it was not statistically different $(81 \%$ vs. $18 \%, \mathrm{p}=0.82)$. Participants who were considered "not at fall risk" had higher mean DST scores (diet quality) and protein scores, but there was no statistical significance $(\mathrm{p}=0.97, \mathrm{p}=0.27)$. There were no significant differences between "not at fall risk" and "at fall risk" in terms of DST total score $(\mathrm{p}=0.97)$, protein score $(\mathrm{p}=0.27)$, multivitamin use $(\mathrm{p}=0.73)$, and DST risk categories $(\mathrm{p}=0.63)$. The means and frequencies of dietary components in STEADI fall risk categories are shown in Table 2.

Table 2. Baseline Diet by STEADI Fall Risk Category

\begin{tabular}{|c|c|c|c|c|}
\hline & Total $(n=180)$ & $\begin{array}{l}\text { Not at fall } \\
\text { risk }(n=65)\end{array}$ & $\begin{array}{c}\text { At fall risk } \\
(n=115)\end{array}$ & $p$-value ${ }^{1}$ \\
\hline \multicolumn{5}{|c|}{ Diet Quality, Protein Intake, \& Vitamin D } \\
\hline DST Score $(0-105)$ & $61.69 \pm 12.51$ & $63.08 \pm 1.55$ & $60.91 \pm 1.17$ & $\mathrm{p}=0.97$ \\
\hline DST protein score $(0-30)$ & $12.84 \pm 4.63$ & $12.86 \pm 0.58$ & $12.83 \pm 0.43$ & $\mathrm{p}=0.27$ \\
\hline Multivitamin use (yes) & $75(41.7 \%)$ & $26(40.0 \%)$ & $49(42.6 \%)$ & $\mathrm{p}=0.73$ \\
\hline \multicolumn{5}{|c|}{ DST nutrition risk categories } \\
\hline At-risk $(<60)$ & $71(39.5 \%)$ & $23(35.4 \%)$ & $48(41.7 \%)$ & \multirow{3}{*}{$\mathrm{p}=0.63$} \\
\hline Possible risk (60-75) & $83(46.1 \%)$ & $31(47.7 \%)$ & $52(45.2 \%)$ & \\
\hline Not-at-risk $(>75)$ & $26(14.4 \%)$ & $11(16.9 \%)$ & $15(13.0 \%)$ & \\
\hline
\end{tabular}




\section{Fall Assessments}

According to the STEADI algorithm, 65 participants answered "no" to all three questions and were categorized as "not at-risk" for falls. Among participants who answered "yes" to any of the three questions $(\mathrm{n}=115)$ and then were categorized as "at fall risk," there were 62 participants who answered "yes" to one of the questions, 33 participants who answered "yes" to two questions, and 20 participants who answered "yes" to all three questions. The summary of the number of participants who answered STEADI questions is illustrated in Table 4.

There were no associations found between gender, race/ethnicity, education level, and income and STEADI risk categories. The means and distribution of STEADI fall risk factors, functional measures, and physical activity are shown in Table 3. There were more fall risk factors such as taking $\geq 4$ medications, arthritis, stroke, diabetes, incontinence, being overweight or obese, and higher depression scores in the "at fall risk" group compared to the "not at fall risk" group. None of the fall risk factors had a significant association with STEADI categories. In terms of functional measures, handgrip strength, FTSTS, TUG, and gait speed did not show a significant difference between STEADI groups. Only the FSST had a statistical trend ( $\mathrm{p}=0.083)$. Specifically, $11.8 \%$ of people in the "at fall risk" category had a greater risk of one or more future falls, while only $3.6 \%$ of people in the "not a fall risk" category had a greater risk of one or more future falls.

Table 3. STEADI Fall Risk Screening in Participants $(\mathrm{N}=180)$ of a Falls Prevention Intervention

\begin{tabular}{lc}
\hline STEADI Categories & Number of Participants \\
\hline Not at fall risk & 65 \\
At fall risk & 115 \\
\hline STEADI Questions & 62 \\
\hline Answered "yes" to one of the questions & 27 \\
Fell within a past year only & 31 \\
Fear of falling only & 4 \\
Unsafe or unsteady while walking & 33 \\
Answered "yes" to two of questions & 19 \\
Fell within the past year \& fear of falling & 5 \\
Fell within the past year \& unsafe or unsteady while walking & 9 \\
Fear of falling \& unsafe or unsteady while walking & 20 \\
Answered "yes" to three of questions & \\
\hline
\end{tabular}


Table 4. Fall Risk Factors by STEADI Risk Category in Participants (N=180) of a Falls Prevention Intervention

\begin{tabular}{|c|c|c|c|c|}
\hline & $\begin{array}{c}\text { Total } \\
(\mathbf{n}=\mathbf{1 8 0})\end{array}$ & $\begin{array}{c}\text { Not at fall risk } \\
(n=65)\end{array}$ & $\begin{array}{l}\text { At fall risk } \\
(n=115)\end{array}$ & $p$-value ${ }^{1}$ \\
\hline \multicolumn{5}{|l|}{ Fall Risk Factors } \\
\hline Age & $70.95 \pm 9.03$ & $70.71 \pm 9.51$ & $71.08 \pm 8.79$ & $\mathrm{p}=0.64$ \\
\hline Takes $\geq 4$ medications (yes) & $113(62.8 \%)$ & $38(58.5 \%)$ & $75(65.2 \%)$ & $\mathrm{p}=0.37$ \\
\hline Arthritis (yes) & $112(64.4 \%)$ & $41(64.1 \%)$ & $71(64.6 \%)$ & $\mathrm{p}=0.95$ \\
\hline Stroke (yes) & $12(6.9 \%)$ & $3(4.8 \%)$ & $9(8.1 \%)$ & $\mathrm{p}=0.40$ \\
\hline Diabetes (yes) & $45(26.0 \%)$ & $15(24.2 \%)$ & $30(27.0 \%)$ & $\mathrm{p}=0.68$ \\
\hline Parkinson (yes) & $1(0.6 \%)$ & 0 & $1(0.9 \%)$ & $\mathrm{p}=0.46$ \\
\hline Incontinence (yes) & $123(68.3 \%)$ & $46(70.1 \%)$ & $77(67.0 \%)$ & $\mathrm{p}=0.60$ \\
\hline \multicolumn{5}{|l|}{ Body Mass Index (BMI) ${ }^{2}$} \\
\hline Normal weight $\left(18.5-24.9 \mathrm{~kg} / \mathrm{m}^{2}\right)$ & $33(18.5 \%)$ & $12(18.8 \%)$ & $21(18.4 \%)$ & \multirow{3}{*}{$\mathrm{p}=0.49$} \\
\hline Overweight $\left(25.0-29.9 \mathrm{~kg} / \mathrm{m}^{2}\right)$ & $60(33.7 \%)$ & $19(29.7 \%)$ & $41(36.0 \%)$ & \\
\hline Obesity $\left(\geq 30 \mathrm{~kg} / \mathrm{m}^{2}\right)$ & $84(47.2 \%)$ & $32(50.0 \%)$ & $52(45.6 \%)$ & \\
\hline WC 'At Risk'3 & $118(66.3 \%)$ & $44(68.8 \%)$ & $74(64.9 \%)$ & $\mathrm{p}=0.60$ \\
\hline Depression $(0-15)$ & $2.02 \pm 2.02$ & $1.77 \pm 2.04$ & $2.16 \pm 2.00$ & $\mathrm{p}=0.13$ \\
\hline Cognition $(0-6)$ & $5.75 \pm 0.61$ & $5.81 \pm 0.53$ & $5.71 \pm 0.65$ & $\mathrm{p}=0.21$ \\
\hline \multicolumn{5}{|c|}{ Functional Measures and Physical Activity } \\
\hline Handgrip Strength ${ }^{4}$ & $25(14.5 \%)$ & $12(18.8 \%)$ & $13(11.9 \%)$ & $\mathrm{p}=0.22$ \\
\hline FTSTS (>15 seconds) $)^{5}$ & $123(77.9 \%)$ & $42(75.0 \%)$ & $81(79.4 \%)$ & $\mathrm{p}=0.52$ \\
\hline FSST (> 15 seconds $)^{6}$ & $14(8.9 \%)$ & $2(3.6 \%)$ & $12(11.8 \%)$ & $\mathrm{p}=0.083$ \\
\hline TUG ( $\geq 12$ seconds $)^{7}$ & $50(28.1 \%)$ & $18(28.1 \%)$ & $32(28.1 \%)$ & $\mathrm{p}=0.99$ \\
\hline Gait speed $(<1 \mathrm{~m} / \mathrm{s})^{8}$ & $60(33.7 \%)$ & $20(31.3 \%)$ & $40(33.7 \%)$ & $\mathrm{p}=0.60$ \\
\hline $\begin{array}{l}\text { Total physical activity } \\
\text { (minutes/week) }\end{array}$ & $162.67 \pm 304.24$ & $139.25 \pm 226.11$ & $175.71 \pm 340.38$ & $\mathrm{p}=0.86$ \\
\hline
\end{tabular}

Values are mean \pm SD or n (\%). Abbreviations: STEADI = Stopping Elderly Accidents, Deaths, and Injuries; BMI = Body Mass Index; WC = Waist Circumference; FTSTS = Five Times Sit-to-Stand; FSST = the Four-Square Step Test; and TUG = Timed Up and Go test. ${ }^{1}$ Significance criterion alpha for all tests was 0.05 , statistical trend was declared when $\mathrm{p}<0.1$ with t-test for normalized continuous variables and Wilcoxon test for unnormalized continuous variables and Chi-square test for categorical variables. ${ }^{2}$ One participant was classified as underweight. ${ }^{3 \text { 'At risk' waist }}$ circumference $\geq 102 \mathrm{~cm}$ in men or $\geq 88 \mathrm{~cm}$ in women. ${ }^{4}$ Cut-off points of $\leq 25.8 \mathrm{~kg}$ for men and $\leq 17.4 \mathrm{~kg}$ for muscle strength problem. ${ }^{5}$ Cut-off points for greater risk of having one or more future falls. ${ }^{6}$ Cut-off points for being a multiple faller. ${ }^{7}$ Cut-off points for greater risk of having one or more future falls. ${ }^{8}$ Cut-off points of gait speed for greater risk of having one or more future falls.

\section{Relationship between Diet and Functional Measures and Fall Risk}

Correlations (r) of total DST scores and protein scores with fall risk factors are listed in Table 4. The DST scores were positively correlated with total physical activity $(\mathrm{r}=0.1648$, $\mathrm{p}=0.029)$, and negatively correlated with BMI $(\mathrm{r}=-0.1496, \mathrm{p}=0.040)$ and depression $(\mathrm{r}=-0.1433$, $\mathrm{p}=0.048$ ). The DST protein scores were positively correlated with total physical activity $(\mathrm{r}=0.2025, \mathrm{p}=0.0072)$. None of the functional measures or fall events were significantly correlated with either DST total scores or protein scores. 
Table 5. Relationship between Sociodemographic Variables, and Functional Measures, and Physical Activity and Diet

\begin{tabular}{|c|c|c|}
\hline & $\begin{array}{c}\text { DST total scores (0-105) } \\
\mathrm{r}(p \text {-value })^{1} \\
\end{array}$ & $\begin{array}{c}\text { DST protein scores (0-30) } \\
\mathrm{r}(p \text {-value })^{1} \\
\end{array}$ \\
\hline \multicolumn{3}{|l|}{ Sociodemographic Variable } \\
\hline Age & $0.1211(\mathrm{p}=0.094)$ & $-0.02(p=0.78)$ \\
\hline BMI $\left(\mathrm{kg} / \mathrm{m}^{2}\right)$ & $-0.1496(p=0.04)$ & $-0.1349(\mathrm{p}=0.062)$ \\
\hline Depression (0-15) & $-0.1433(p=0.048)$ & $0.0257(\mathrm{p}=0.62)$ \\
\hline Cognition (0-6) & $0.0544(\mathrm{p}=0.46)$ & $-0.1025(\mathrm{p}=0.16)$ \\
\hline \multicolumn{3}{|l|}{ Fall Events } \\
\hline Fall history ${ }^{1}$ & $0.0493(\mathrm{p}=0.50)$ & $-0.0273(\mathrm{p}=0.71)$ \\
\hline Fall injury ${ }^{2}$ & $-0.0418(p=0.57)$ & $-0.0723(\mathrm{p}=0.32)$ \\
\hline \multicolumn{3}{|c|}{ Functional Measures \& Physical Activity } \\
\hline Grip strength $(\mathrm{kg})$ & $-0.0052(p=0.94)$ & $0.1359(\mathrm{p}=0.067)$ \\
\hline FTSTS (seconds) & $-0.0049(p=0.95)$ & $0.0811(\mathrm{p}=0.30)$ \\
\hline Gait speed (meters/seconds) & $0.0785(\mathrm{p}=0.28)$ & $0.0235(\mathrm{p}=0.75)$ \\
\hline FSST (seconds) & $-0.0042(p=0.96)$ & $-0.1073(\mathrm{p}=0.17)$ \\
\hline TUG (seconds) & $-0.0282(\mathrm{p}=0.70)$ & $0.0006(\mathrm{p}=0.99)$ \\
\hline Total Physical Activity (minutes) & $0.1648(\mathrm{p}=0.029)$ & $0.2025(\mathrm{p}=0.0072)$ \\
\hline
\end{tabular}

\section{Relationship between Diet and Fall Risk}

In each multivariate model in Table 5, the adjusting variables (i.e., BMI, depression, total physical activity, grip strength, FSST) were used based on the previous significances or statistical trends of the t-test, Wilcoxon, Chi-square, or Spearman's correlation tests. None of the primary predictors, such as total DST score or DST protein score, showed a significant impact on fall risk when adjusted for covariates. In each model, FSST had the smallest likelihood ratio test p-value indicating the balance problem may be the major component for affecting STEADI fall risk groups (Model 1: $\mathrm{p}=0.10$, Model 2: $\mathrm{p}=0.15$ ) 
Table 6. The Relationships of Baseline Diet, Adjustment Variables and STEADI Categories (N=180)

\begin{tabular}{|c|c|c|c|c|c|}
\hline $\begin{array}{l}\text { The } \\
\text { predictor } \\
\text { model }\end{array}$ & $\begin{array}{c}\text { Primary } \\
\text { predictor \& } \\
\text { Covariates }\end{array}$ & $\beta$ (SE) & $\begin{array}{c}\text { Parameter } \\
\text { estimate } \\
\text { p-value }\end{array}$ & $\begin{array}{c}\text { Odds Ratio } \\
\text { (95\% Wald } \\
\text { Confidence } \\
\text { Limits) }\end{array}$ & $\begin{array}{c}\text { Likelihood } \\
\text { ratio test } \\
\text { p-value }{ }^{1}\end{array}$ \\
\hline \multirow[t]{5}{*}{ Model 1} & $\begin{array}{l}\text { Primary: } \\
\text { DST score }\end{array}$ & $-0.0093(0.0150)$ & 0.53 & $0.99(0.96,1.02)$ & 0.53 \\
\hline & 1. BMI & $-0.0358(0.0312)$ & 0.25 & $0.96(0.91,1.03)$ & 0.25 \\
\hline & 2. Depression & $0.0417(0.0896)$ & 0.64 & $1.04(0.87 .1 .24)$ & 0.64 \\
\hline & $\begin{array}{l}\text { 3. Total Physical } \\
\text { Activity }\end{array}$ & $0.0003(0.0006)$ & 0.60 & $1.00(0.99,1.00)$ & 0.57 \\
\hline & 4. FSST & $-0.5882(0.3400)$ & 0.14 & $3.24(0.68,15.55)^{2}$ & 0.10 \\
\hline \multirow[t]{6}{*}{ Model 2} & $\begin{array}{l}\text { Primary: DST } \\
\text { protein score }\end{array}$ & $-0.0009(0.0410)$ & 0.99 & $0.99(0.92,1.08)$ & 0.98 \\
\hline & 1. BMI & $-0.0331(0.0316)$ & 0.30 & $0.97(0.91,1.03)$ & 0.29 \\
\hline & 2. Depression & $0.0470(0.0895)$ & 0.60 & $1.05(0.88,1.25)$ & 0.60 \\
\hline & $\begin{array}{l}\text { 3. Total Physical } \\
\text { Activity }\end{array}$ & $0.0004(0.0006)$ & 0.54 & $1.00(0.99,1.00)$ & 0.53 \\
\hline & 4. Grip Strength & $-0.0042(0.0231)$ & 0.86 & $0.99(0.95,1.04)$ & 0.86 \\
\hline & 5. FSST & $-0.5337(0.4066)$ & 0.19 & $2.91(0.59,14.31)^{2}$ & 0.15 \\
\hline
\end{tabular}

Abbreviations: BMI = Body Mass Index; FSST = the Four-Square Step test. ${ }^{1}$ Significance criterion alpha for all tests was 0.05 , and the statistical trend was declared when $p<0.1^{2}$ Odds ratio of risk falling in participants with balance problem to risk of fall in no balance problem- participants was determined. 


\section{CHAPTER 5: DISCUSSION AND CONCLUSION}

In this cross-sectional study of community-dwelling older adults participating in a fallprevention intervention $(n=192)$, the diet was not associated with functional measures and fall risk. However, there was a significant correlation between diet (i.e., diet quality and protein intake) and minutes of physical activity per week. This finding is consistent with other studies. In a cross-sectional study of older adults at least 85 years old $(n=819)$, the association between dietary intake and physical activity were compared [23]. This cross-sectional study found that the total Elderly Diet Index score was associated with physical activity participating in at least $150 \mathrm{~min}$ of moderate-intensity aerobic physical activity or at least $75 \mathrm{~min}$ of vigorous-intensity aerobic physical activity throughout the week $(\mathrm{OR}=4.99 ; 95 \%$ CI 3.20 to 7.70) [23]. Elderly participants who had a higher diet score had about five times the odds of doing 75 minutes of vigorous exercise during the week than the elderly participants with a lower diet score [23]. This cross-sectional study is consistent with our finding that higher diet quality is correlated with increased minutes of physical activity.

A significant relationship was not detected between protein intake as measured by the DST scores and functional measures. Other studies found significant associations of protein intake with functional measures or falls when those studies measured the actual amount of protein intake. The Framingham Cohort study $(n=807)$ had estimated total and animal protein intakes based on the 126-item Willett Food Frequency Questionnaire. That study showed associations such as higher dietary protein intake decreased the odds of falling, although these were of borderline statistical significance $(\mathrm{OR}=0.80,95 \% \mathrm{CI}: 0.60-1.07)$, and participants with a weight loss of $\geq 5 \%$ had decreased rates of falls with higher protein intake $(p=0.03)$ [26]. In another Framingham Offspring Cohort study, the 126-item Willett Food Frequency Questionnaire was used to examine the associations between protein intake (total, animal, and plant) and grip strength among 1,746 older adults [8]. As a result, greater protein intake (total 
and animal protein) was shown to be protective against the loss of grip strength $(\mathrm{p}<0.05)[8]$. Unlike our study, this study identified the sources of protein intake, such as animal or plant protein. Likewise, distinguishing protein sources made statistically significant results in other studies $[8,26,28]$. Our study had only protein sources enumerated from lean protein, dairy products, and processed meat.

Other studies used a 24-hour recall or a 3-day food record to measure protein intake. Mishra et al. used 24-hour recall to measure the protein intake for analyzing the association between protein intake and grip strength [24]. In adults aged 51 years or older $(n=4,123)$, having at least 25 grams of protein in two or more meals and snacks was not associated with grip strength, but a positive association was found between grip strength and protein intake in women with protein intakes in the third and fourth quartiles (mean intakes of 71.4 and $104.1 \mathrm{~g}$, respectively) compared to the lowest quartile $(33.6 \mathrm{~g})(\mathrm{p}<0.05)$ [24]. Another study examined the associations between protein intake measured by a 3-day food record and functional measures [7]. Women with higher protein intake ( $\geq 1.2 \mathrm{~g} / \mathrm{kg} \mathrm{BW})$ had better performance in hand-grip strength $(\mathrm{p}=0.001)$ than women with lower protein intake $(<1.2 \mathrm{~g} / \mathrm{kg} \mathrm{BW})$ at the baseline [7].

It should be noted that in this study, DST asks questions related to protein quality rather than amount of protein. Other studies used a food frequency questionnaire, food records, or 24hour recalls to assess the amount of protein intake rather than the quality of protein foods consumed. This can explain why we did not detect a relationship between protein and functional measures.

In our study, a relationship was not detected between vitamin D and fall risk categories. STEADI recommends a vitamin D supplement to older adults with vitamin D deficiencies for fall prevention [32]. In 2012, USPSTF recommended vitamin D supplementations at 600 IU for adults age 51 to 70 years old and 800 IU for adults older than 70 years to prevent falls in 
community-dwelling adults 65 years or older [34]. However, in 2018, this recommendation was updated to state that vitamin D supplementation is not recommended to prevent falls among community-dwelling adults without vitamin D deficiency [32]. When STEADI or USPSTF made the vitamin D recommendations, the clinical trials with measurements of dosages of vitamin D were evaluated. Our cross-sectional study had the proxy measure of vitamin D instead of the dosage amount. Also, STEADI recommendations were focused on older adults with vitamin D deficiencies. However, our study did not utilize any tools for identifying vitamin D deficiency in the participants.

\section{Nutrition Risk}

In this study population, $39.5 \%$ of participants were classified as nutritionally being "at-risk," $46.1 \%$ were at "possible-risk," and $14.4 \%$ were "not-at-risk". The proportion of participants at nutrition risk differed from another study sample. In a study of 204 older adults in rural areas, $28 \%$ were "at-risk," $46 \%$ were in the "possible-risk" category, and $26 \%$ were in the "not-at-risk" category [34]. In a sample of 355 Congregate Meal Site Participants, 36\% were "at-risk," 39\% were at "possible-risk," and 10\% were "not-at-risk" [21]. In the third study of 392 community-residing older adults, $26 \%$ were "at-risk," $54 \%$ were at "possible-risk," and $20 \%$ were "not-at-risk" [39]. Compared to the other three studies, our study had the highest percentage of "at-risk" group with the smallest population. For all studies, the "possible-risk" group had the highest percentage compared to "at-risk" and "not-at-risk" groups.

The participants of previous studies were older adults. In the middle-aged population in West Virginia $(n=87)$, there was different distribution in the DST categories. Compared to our study, the middle-aged population had a higher percentage of participants "at-risk" (a $64.6 \%)$ and a lower percentage of participants at "possible-risk" or "not-at-risk" (35.4\%) [38]. When the DST was used on different age groups, the distribution of DST categories was shown differently. 


\section{Fall Assessment}

Our study used cut-off values of functional measures to examine muscle strength, physical performance, balance, or mobility problems. Other studies use cut-off values associated with other endpoints. For instance, Vasconcelos et al. had different cut-off values of gait speed $(0.8 \mathrm{~m} / \mathrm{s})$ form our study, which used the cut-off value of $1 \mathrm{~m} / \mathrm{s}$ [35]. The cut-off values by Vasconcelos were intended to identify the mobility limitations $[14,45]$. Our study used cut-off points for gait speed related to the risk of having one or more future falls, not mobility limitations. If we used different cut-off values with proper indicators, the assessment of functional measures with diet or fall risk could differ.

\section{Strengths and Limitations}

A primary strength of this study is that there were objective measures of muscle strength, physical performance, balance, and mobility. There were some limitations to this study. First, the population of this study was predominantly Non-Hispanic, white participants (85.9\%), which is a characteristic population for West Virginia (94.6\%). Thus, the findings may not be generalized to other populations or ethnicities. Second, the DST does not measure the amount of protein consumed. Vitamin D was a proxy measure, while other studies used food frequency questionnaires or food records. Also, the DST assesses diet quality not the actual amount of protein intake and vitamin D. Because our study was composed of older adults, the DST was an effective tool for dietary measurements that could be completed in less than 10 minutes compared to food records or food frequency questionnaires, which usually took a long time. Even if the amount of protein or vitamin D intake was measured, that amount could be under- or overreported. Third, this study used three key questions for STEADI fall risk categories. There is a different measure to categorize STEADI fall risk categories: Stay Independent, which is composed of twelve questions. If our study was able to use the Stay Independent: 12-question tool instead of using three key questions, the distribution of fall risk 
categories in STEADI might be different. Lastly, the cross-sectional study characteristics examine the association, not the causation.

\section{Conclusion}

This study did not find a relationship between diet, functional measures, and fall risk. Our findings contradicted the literature review that higher dietary quality likely leads to better functional measures (i.e., muscle strength, balance, mobility, and physical performance), which lead to reduced fall risk. Any nutritional recommendations for fall prevention could not be made according to our findings. More research on the relationship between nutrition, functional measures, and fall risk is needed. Different fall screening tools or diet assessments such as food frequency questionnaires or food records could show different results from our study. Preferably, prospective studies with the measurements of the actual protein intakes or vitamin D supplementation are necessary to confirm the presence or absence of these associations. 


\section{Appendix}

Table 7. Dietary Screening Tool [45]

\begin{tabular}{|c|c|}
\hline DST Component & $\begin{array}{l}\text { Point } \\
\text { Classification }\end{array}$ \\
\hline $\begin{array}{l}\text { Whole fruit and juice } \\
\text { - How often do you usually eat fruit as a snack? } \\
\text { - How often do you eat fruit (not including juice)? } \\
\text { - How often do you drink some kind of juice at breakfast? }\end{array}$ & $\begin{array}{l}15 \\
(5) \\
(5) \\
(5)\end{array}$ \\
\hline $\begin{array}{l}\text { Vegetables } \\
\text { - How often do you eat carrots, sweet potatoes, broccoli, or spinach? } \\
\text { - How many different vegetable servings do you usually have at your } \\
\text { main meal of the day? }\end{array}$ & $\begin{array}{l}15 \\
(8) \\
(7)\end{array}$ \\
\hline $\begin{array}{l}\text { Total and whole grains } \\
\text { - How often do you usually eat whole-grain breads? } \\
\text { - How often do you usually eat whole-grain cereals? } \\
\text { - How often do you eat hot or cold breakfast cereal? }\end{array}$ & $\begin{array}{l}15 \\
(5) \\
(5) \\
(5)\end{array}$ \\
\hline $\begin{array}{l}\text { Lean Proteins } \\
\text { - How often do you eat chicken or turkey? } \\
\text { - How often do you eat fish or seafood that is not fried? }\end{array}$ & $\begin{array}{l}10 \\
(5) \\
(5)\end{array}$ \\
\hline $\begin{array}{l}\text { Added fats, sugars, and sweets } \\
\text { - How often do you usually eat candy or chocolate? } \\
\text { - How often do you eat crackers, pretzels, chips, or popcorn? } \\
\text { - How often do you eat cakes or pies? } \\
\text { - How often do you eat cookies? } \\
\text { - How often do you eat ice cream? } \\
\text { - Do you usually add butter or margarine to foods such as bread, rolls, } \\
\text { - or biscuits? } \\
\text { - Do you usually add fat (butter, margarine or oil) to potatoes and other } \\
\text { - Do you use gravy (when available) at meals? } \\
\text { - Do you usually add sugar or honey to sweeten your coffee or tea? } \\
\text { - Do you usually drink wine, beer, or other alcoholic beverages? }\end{array}$ & $\begin{array}{l}25 \\
(4) \\
(4) \\
(4) \\
(4) \\
(4) \\
(1) \\
(1) \\
(1) \\
(1) \\
(1)\end{array}$ \\
\hline $\begin{array}{l}\text { Dairy } \\
\text { - How often do you drink a glass of milk? } \\
\text { - How many servings of milk, cheese, or yogurt do you usually have } \\
\text { each day? }\end{array}$ & $\begin{array}{l}10 \\
(5) \\
(5)\end{array}$ \\
\hline $\begin{array}{l}\text { Processed meats } \\
\text { - How often do you eat cold cuts, hot dogs, lunchmeats, or deli meats? } \\
\text { - How often do you eat bacon or sausage? }\end{array}$ & $\begin{array}{l}10 \\
(5) \\
(5)\end{array}$ \\
\hline Total & 100 \\
\hline Dietary Supplement use & +5 \\
\hline
\end{tabular}




\section{REFERENCES}

1. Materials for Healthcare Providers | STEADI - Older Adult Fall Prevention | CDC Injury Center Available online: https://www.cdc.gov/steadi/materials.html (accessed on Feb 17, 2020).

2. CDC Important Facts about Falls $\mid$ Home and Recreational Safety $\mid$ CDC Injury Center Available online: https://www.cdc.gov/homeandrecreationalsafety/falls/adultfalls.html (accessed on Apr 11, 2019).

3. Make STEADI Part of Your Medical Practice | STEADI - Older Adult Fall Prevention | CDC Injury Center Available online: https://www.cdc.gov/steadi/index.html (accessed on Mar 6, 2019).

4. Panel on Prevention of Falls in Older Persons, American Geriatrics Society and British Geriatrics Society Summary of the Updated American Geriatrics Society/British Geriatrics Society clinical practice guideline for prevention of falls in older persons. $J$ Am Geriatr Soc 2011, 59, 148-157, doi:10.1111/j.1532-5415.2010.03234.x.

5. Renfro, M.; Maring, J.; Bainbridge, D.; Blair, M. Fall Risk Among Older Adult High-Risk Populations: a Review of Current Screening and Assessment Tools. Curr Geri Rep 2016, 5, 160-171, doi:10.1007/s13670-016-0181-x.

6. Kim, J.; Lee, Y.; Kye, S.; Chung, Y.-S.; Kim, K.-M. Association between healthy diet and exercise and greater muscle mass in older adults. $J$ Am Geriatr Soc 2015, 63, 886-892, doi:10.1111/jgs.13386.

7. Isanejad, M.; Mursu, J.; Sirola, J.; Kröger, H.; Rikkonen, T.; Tuppurainen, M.; Erkkilä, A.T. Dietary protein intake is associated with better physical function and muscle strength among elderly women. Br. J. Nutr. 2016, 115, 1281-1291, doi:10.1017/S000711451600012X.

8. McLean, R.R.; Mangano, K.M.; Hannan, M.T.; Kiel, D.P.; Sahni, S. Dietary Protein Intake 
Is Protective Against Loss of Grip Strength Among Older Adults in the Framingham Offspring Cohort. J. Gerontol. A Biol. Sci. Med. Sci. 2016, 71, 356-361, doi:10.1093/gerona/glv184.

9. Bloom, I.; Shand, C.; Cooper, C.; Robinson, S.; Baird, J. Diet Quality and Sarcopenia in Older Adults: A Systematic Review. Nutrients 2018, 10, doi:10.3390/nu10030308.

10. Robinson, S.M.; Westbury, L.D.; Cooper, R.; Kuh, D.; Ward, K.; Syddall, H.E.; Sayer, A.A.; Cooper, C. Adult Lifetime Diet Quality and Physical Performance in Older Age: Findings From a British Birth Cohort. J Gerontol A Biol Sci Med Sci 2018, 73, 1532-1537, doi:10.1093/gerona/glx179.

11. Daly, R.M. Independent and Combined Effects of Exercise and Vitamin D on Muscle Morphology, Function and Falls in the Elderly. Nutrients 2010, 2, 1005-1017, doi:10.3390/nu2091005.

12. Sherrington, C.; Fairhall, N.J.; Wallbank, G.K.; Tiedemann, A.; Michaleff, Z.A.; Howard, K.; Clemson, L.; Hopewell, S.; Lamb, S.E. Exercise for preventing falls in older people living in the community. Cochrane Database Syst Rev 2019, 1, CD012424, doi:10.1002/14651858.CD012424.pub2.

13. Morley, J.E.; Argiles, J.M.; Evans, W.J.; Bhasin, S.; Cella, D.; Deutz, N.E.P.; Doehner, W.; Fearon, K.C.H.; Ferrucci, L.; Hellerstein, M.K.; et al. Nutritional recommendations for the management of sarcopenia. J Am Med Dir Assoc 2010, 11, 391-396, doi:10.1016/j.jamda.2010.04.014.

14. Dodds, R.M.; Roberts, H.C.; Cooper, C.; Sayer, A.A. The Epidemiology of Sarcopenia. J Clin Densitom 2015, 18, 461-466, doi:10.1016/j.jocd.2015.04.012.

15. Landi, F.; Liperoti, R.; Russo, A.; Giovannini, S.; Tosato, M.; Capoluongo, E.; Bernabei, R.; Onder, G. Sarcopenia as a risk factor for falls in elderly individuals: results from the ilSIRENTE study. Clin Nutr 2012, 31, 652-658, doi:10.1016/j.clnu.2012.02.007. 
16. Li, F.; Harmer, P.; Fitzgerald, K.; Eckstrom, E.; Akers, L.; Chou, L.-S.; Pidgeon, D.; Voit, J.; Winters-Stone, K. Effectiveness of a Therapeutic Tai Ji Quan Intervention vs a Multimodal Exercise Intervention to Prevent Falls Among Older Adults at High Risk of Falling: A Randomized Clinical Trial. JAMA Intern Med 2018, 178, 1301-1310, doi:10.1001/jamainternmed.2018.3915.

17. Eckstrom, E.; Parker, E.M.; Lambert, G.H.; Winkler, G.; Dowler, D.; Casey, C.M. Implementing STEADI in Academic Primary Care to Address Older Adult Fall Risk. Innov Aging 2017, 1, doi:10.1093/geroni/igx028.

18. Lohman, M.C.; Crow, R.S.; DiMilia, P.R.; Nicklett, E.J.; Bruce, M.L.; Batsis, J.A. Operationalization and Validation of the Stopping Elderly Accidents, Deaths, and Injuries (STEADI) Fall Risk Algorithm in a Nationally Representative Sample. J Epidemiol Community Health 2017, 71, 1191-1197, doi:10.1136/jech-2017-209769.

19. Moreland, J.D.; Richardson, J.A.; Goldsmith, C.H.; Clase, C.M. Muscle weakness and falls in older adults: a systematic review and meta-analysis. J Am Geriatr Soc 2004, 52, 1121-1129, doi:10.1111/j.1532-5415.2004.52310.x.

20. Kim, H.; Kwon, O. Higher Diet Quality is Associated with Lower Odds of Low Hand Grip Strength in the Korean Elderly Population. Nutrients 2019, 11, doi:10.3390/nu11071487.

21. Smee, D.J.; Pumpa, K.; Falchi, M.; Lithander, F.E. The relationship between diet quality and falls risk, physical function and body composition in older adults. J Nutr Health Aging 2015, 19, 1037-1042, doi:10.1007/s12603-015-0666-x.

22. Guirguis-Blake, J.M.; Michael, Y.L.; Perdue, L.A.; Coppola, E.L.; Beil, T.L. Interventions to Prevent Falls in Older Adults: Updated Evidence Report and Systematic Review for the US Preventive Services Task Force. JAMA 2018, 319, 1705-1716, doi:10.1001/jama.2017.21962. 
23. Štefan, L.; Petrinović, L.; Sporiš, G.; Vrgoč, G. Frequency of Dietary Intake and Physical Activity in Older Adults: A Cross-Sectional Study. Nutrients 2018, 10, doi:10.3390/nu10121960.

24. Mishra, S.; Goldman, J.D.; Sahyoun, N.R.; Moshfegh, A.J. Association between dietary protein intake and grip strength among adults aged 51 years and over: What We Eat in America, National Health and Nutrition Examination Survey 2011-2014. PLoS ONE 2018, 13, e0191368, doi:10.1371/journal.pone.0191368.

25. Ten Haaf, D.S.M.; van Dongen, E.J.I.; Nuijten, M.A.H.; Eijsvogels, T.M.H.; de Groot, L.C.P.G.M.; Hopman, M.T.E. Protein Intake and Distribution in Relation to Physical Functioning and Quality of Life in Community-Dwelling Elderly People: Acknowledging the Role of Physical Activity. Nutrients 2018, 10, doi:10.3390/nu10040506.

26. Zoltick, E.S.; Sahni, S.; McLean, R.R.; Quach, L.; Casey, V.A.; Hannan, M.T. Dietary protein intake and subsequent falls in older men and women: the Framingham Study. J Nutr Health Aging 2011, 15, 147-152.

27. Larocque, S.C.; Kerstetter, J.E.; CAULEY, J.A.; Insogna, K.L.; Ensurd, K.; Lui, L.-Y.; Allore, H.G. Dietary Protein and Vitamin D Intake and Risk of Falls: A Secondary Analysis ofPostmenopausal Women from the Study of Osteoporotic Fractures. J Nutr Gerontol Geriatr 2015, 34, 305-318, doi:10.1080/21551197.2015.1054574.

28. Sellmeyer, D.E.; Stone, K.L.; Sebastian, A.; Cummings, S.R. A high ratio of dietary animal to vegetable protein increases the rate of bone loss and the risk of fracture in postmenopausal women. Study of Osteoporotic Fractures Research Group. Am. J. Clin. Nutr. 2001, 73, 118-122, doi:10.1093/ajcn/73.1.118.

29. Sandoval-Insausti, H.; Pérez-Tasigchana, R.F.; López-García, E.; Banegas, J.R.; Rodríguez-Artalejo, F.; Guallar-Castillón, P. Protein Intake and Risk of Falls: A Prospective Analysis in Older Adults. J Am Geriatr Soc 2019, 67, 329-335, doi:10.1111/jgs.15681. 
30. Neelemaat, F.; Lips, P.; Bosmans, J.E.; Thijs, A.; Seidell, J.C.; van Bokhorst-de van der Schueren, M.A.E. Short-term oral nutritional intervention with protein and vitamin D decreases falls in malnourished older adults. J Am Geriatr Soc 2012, 60, 691-699, doi:10.1111/j.1532-5415.2011.03888.x.

31. Dawson-Hughes, B. Serum 25-hydroxyvitamin D and functional outcomes in the elderly. Am. J. Clin. Nutr. 2008, 88, 537S-540S, doi:10.1093/ajen/88.2.537S.

32. Murad, M.H.; Elamin, K.B.; Abu Elnour, N.O.; Elamin, M.B.; Alkatib, A.A.; Fatourechi, M.M.; Almandoz, J.P.; Mullan, R.J.; Lane, M.A.; Liu, H.; et al. Clinical review: The effect of vitamin D on falls: a systematic review and meta-analysis. J. Clin. Endocrinol. Metab. 2011, 96, 2997-3006, doi:10.1210/jc.2011-1193.

33. Smith, L.M.; Gallagher, J.C.; Suiter, C. Medium doses of daily vitamin D decrease falls and higher doses of daily vitamin D3 increase falls: A randomized clinical trial. J. Steroid Biochem. Mol. Biol. 2017, 173, 317-322, doi:10.1016/j.jsbmb.2017.03.015.

34. Moyer, V.A.; U.S. Preventive Services Task Force Prevention of falls in communitydwelling older adults: U.S. Preventive Services Task Force recommendation statement. Ann. Intern. Med. 2012, 157, 197-204, doi:10.7326/0003-4819-157-3-201208070-00462.

35. Ventura Marra, M.; Thuppal, S.V.; Johnson, E.J.; Bailey, R.L. Validation of a Dietary Screening Tool in a Middle-Aged Appalachian Population. Nutrients 2018, 10, doi:10.3390/nu10030345.

36. Bailey, R.L.; Miller, P.E.; Mitchell, D.C.; Hartman, T.J.; Lawrence, F.R.; Sempos, C.T.; Smiciklas-Wright, H. Dietary screening tool identifies nutritional risk in older adults123. Am J Clin Nutr 2009, 90, 177-183, doi:10.3945/ajcn.2008.27268.

37. Liu, Y.-H.; Gao, X.; Mitchell, D.C.; Wood, G.C.; Bailey, R.K.; Still, C.D.; Jensen, G.L. Validation of a Diet Quality Screening Tool for Use in the Oldest Old. J Nutr Gerontol Geriatr 2019, 1-9, doi:10.1080/21551197.2019.1601604. 
38. Lillehoj, C.J.; Yap, L.; Montgomery, D.; Shelley, M.; Francis, S.L. Nutritional Risk among Congregate Meal Site Participants: Benefits of a SNAP-Ed Program. J Nutr Gerontol Geriatr 2018, 37, 204-217, doi:10.1080/21551197.2018.1516592.

39. Bailey, R.L.; Mitchell, D.C.; Miller, C.K.; Still, C.D.; Jensen, G.L.; Tucker, K.L.; Smiciklas-Wright, H. A dietary screening questionnaire identifies dietary patterns in older adults. J. Nutr. 2007, 137, 421-426, doi:10.1093/jn/137.2.421.

40. Ford, D.W.; Jensen, G.L.; Still, C.; Wood, C.; Mitchell, D.C.; Erickson, P.; Bailey, R.; Smiciklas-Wright, H.; Coffman, D.L.; Hartman, T.J. The associations between diet quality, Body Mass Index (BMI) and Health and Activity Limitation Index (HALex) in the Geisinger Rural Aging Study (GRAS). J Nutr Health Aging 2014, 18, 167-170, doi:10.1007/s12603-014-0016-4.

41. Smee, D.; Pumpa, K.; Falchi, M.; Lithander, F.E. The Relationship between Diet Quality and Falls Risk, Physical Function and Body Composition in Older Adults. J Nutr Health Aging 2015, 19, 1037-1042, doi:10.1007/s12603-015-0542-8.

42. Houston, D.K.; Nicklas, B.J.; Ding, J.; Harris, T.B.; Tylavsky, F.A.; Newman, A.B.; Lee, J.S.; Sahyoun, N.R.; Visser, M.; Kritchevsky, S.B.; et al. Dietary protein intake is associated with lean mass change in older, community-dwelling adults: the Health, Aging, and Body Composition (Health ABC) Study. Am. J. Clin. Nutr. 2008, 87, 150-155, doi:10.1093/ajen/87.1.150.

43. McLean, R.R.; Mangano, K.M.; Hannan, M.T.; Kiel, D.P.; Sahni, S. Dietary Protein Intake Is Protective Against Loss of Grip Strength Among Older Adults in the Framingham Offspring Cohort. J. Gerontol. A Biol. Sci. Med. Sci. 2016, 71, 356-361, doi:10.1093/gerona/glv184.

44. Radavelli-Bagatini, S.; Zhu, K.; Lewis, J.R.; Dhaliwal, S.S.; Prince, R.L. Association of dairy intake with body composition and physical function in older community-dwelling 
women. J Acad Nutr Diet 2013, 113, 1669-1674, doi:10.1016/j.jand.2013.05.019.

45. Dodds, R.M.; Syddall, H.E.; Cooper, R.; Benzeval, M.; Deary, I.J.; Dennison, E.M.; Der, G.; Gale, C.R.; Inskip, H.M.; Jagger, C.; et al. Grip Strength across the Life Course: Normative Data from Twelve British Studies. PLoS One 2014, 9, doi:10.1371/journal.pone.0113637.

46. Jones, C.J.; Rikli, R.E.; Beam, W.C. A 30-s chair-stand test as a measure of lower body strength in community-residing older adults. Res $Q$ Exerc Sport 1999, 70, 113-119, doi:10.1080/02701367.1999.10608028.

47. Gusi, N.; Carmelo Adsuar, J.; Corzo, H.; del Pozo-Cruz, B.; Olivares, P.R.; Parraca, J.A. Balance training reduces fear of falling and improves dynamic balance and isometric strength in institutionalised older people: a randomised trial. Journal of Physiotherapy 2012, 58, 97-104, doi:10.1016/S1836-9553(12)70089-9.

48. Viccaro, L.J.; Perera, S.; Studenski, S.A. Is Timed Up and Go Better Than Gait Speed in Predicting Health, Function, and Falls in Older Adults? J Am Geriatr Soc 2011, 59, 887892, doi:10.1111/j.1532-5415.2011.03336.x.

49. Abu Samah, Z.; Mohd Nordin, N.A.; Shahar, S.; Singh, D.K.A. Can gait speed test be used as a falls risk screening tool in community dwelling older adults? A review. Polish Annals of Medicine 2016, 23, 61-67, doi:10.1016/j.poamed.2015.04.007.

50. Espy, D.D.; Yang, F.; Bhatt, T.; Pai, Y.-C. Independent influence of gait speed and step length on stability and fall risk. Gait \& Posture 2010, 32, 378-382, doi:10.1016/j.gaitpost.2010.06.013.

51. Chan, B.K.S.; Marshall, L.M.; Winters, K.M.; Faulkner, K.A.; Schwartz, A.V.; Orwoll, E.S. Incident fall risk and physical activity and physical performance among older men: the Osteoporotic Fractures in Men Study. Am. J. Epidemiol. 2007, 165, 696-703, doi:10.1093/aje/kwk050. 
52. Jones, D.L.; Starcher, R.W.; Eicher, J.L.; Wilcox, S. Adoption of a Tai Chi Intervention, Tai Ji Quan: Moving for Better Balance, for Fall Prevention by Rural Faith-Based Organizations, 2013-2014. Prev Chronic Dis 2016, 13, doi:10.5888/pcd13.160083.

53. Cruz-Jentoft, A.J.; Baeyens, J.P.; Bauer, J.M.; Boirie, Y.; Cederholm, T.; Landi, F.; Martin, F.C.; Michel, J.-P.; Rolland, Y.; Schneider, S.M.; et al. Sarcopenia: European consensus on definition and diagnosis: Report of the European Working Group on Sarcopenia in Older People. Age Ageing 2010, 39, 412-423, doi:10.1093/ageing/afq034.

54. Vasconcelos, K.S. de S.; Dias, J.M.D.; Bastone, A. de C.; Vieira, R.A.; Andrade, A.C. de S.; Perracini, M.R.; Guerra, R.O.; Dias, R.C. Handgrip Strength Cutoff Points to Identify Mobility Limitation in Community-dwelling Older People and Associated Factors. J Nutr Health Aging 2016, 20, 306-315, doi:10.1007/s12603-015-0584-y.

55. Kyrdalen, I.L.; Thingstad, P.; Sandvik, L.; Ormstad, H. Associations between gait speed and well-known fall risk factors among community-dwelling older adults. Physiother Res Int 2019, 24, e1743, doi:10.1002/pri.1743.

56. Cesari, M.; Kritchevsky, S.B.; Newman, A.B.; Simonsick, E.M.; Harris, T.B.; Penninx, B.W.; Brach, J.S.; Tylavsky, F.A.; Satterfield, S.; Bauer, D.C.; et al. Added Value of Physical Performance Measures in Predicting Adverse Health-Related Events: Results from the Health, Aging, and Body Composition Study. J Am Geriatr Soc 2009, 57, 251259, doi:10.1111/j.1532-5415.2008.02126.x.

57. Dite, W.; Temple, V.A. A clinical test of stepping and change of direction to identify multiple falling older adults. Arch Phys Med Rehabil 2002, 83, 1566-1571.

58. NHANES - National Health and Nutrition Examination Survey Homepage Available online: https://www.cdc.gov/nchs/nhanes/index.htm (accessed on Apr 11, 2020).

59. About Adult BMI | Healthy Weight | CDC Available online: https://www.cdc.gov/healthyweight/assessing/bmi/adult_bmi/index.html (accessed on Jan 
23, 2019).

60. Losing Weight, Body Mass Iindex Available online: https://www.nhlbi.nih.gov/health/educational/lose_wt/BMI/bmi_dis.htm (accessed on Jul 26, 2019).

61. Matias, A.G.C.; Fonsêca, M. de A.; Gomes, M. de L. de F.; Matos, M.A.A. Indicators of depression in elderly and different screening methods. Einstein (Sao Paulo) 2016, 14, 611, doi:10.1590/S1679-45082016AO3447.

62. Callahan, C.M.; Unverzagt, F.W.; Hui, S.L.; Perkins, A.J.; Hendrie, H.C. Six-item screener to identify cognitive impairment among potential subjects for clinical research. Med Care 2002, 40, 771-781, doi:10.1097/01.MLR.0000024610.33213.C8.

63. Long, L.S.; Shapiro, W.A.; Leung, J.M. A brief review of practical preoperative cognitive screening tools. Can J Anesth/J Can Anesth 2012, 59, 798-804, doi:10.1007/s12630-0129737-1.

64. MacNab, L.; Francis, S.L.; Lofgren, I.; Violette, C.; Shelley, M.C.; Delmonico, M.; Xu, F. Factors Influencing Dietary Intake Frequencies and Nutritional Risk among CommunityResiding Older Adults. $J$ Nutr Gerontol Geriatr 2018, 1-14, doi:10.1080/21551197.2018.1524809. 